\title{
ANÁLISE SOBRE EFICIÊNCIA EM MERCADOS FUTUROS: UMA COMPARAÇÃO ENTRE OS CONTRATOS DE ALGODÃO EM PLUMA DA BM\&F E DA NYBOT
}

\section{FABIANA SALGUEIRO PEROBELLI}

Economista

Orientador: Prof. Dr. PEDRO CARVALHO DE MELLO

Dissertação apresentada à Escola Superior de Agricultura "Luiz de Queiroz", Universidade de São Paulo, para obtenção do título de Mestre em Ciências, Área de concentração: Economia Aplicada.

\author{
PIRACICABA \\ Estado de São Paulo - Brasil \\ Julho - 2001
}




\title{
Dados Internacionais de Catalogação na Publicação (CIP) DIVISÃo DE BIBLIOTECA E DOCUMENTAÇĀO - Campus "Luiz de Queiroz"/USP
}

\author{
Perobelli, Fabiana Salgueiro \\ Anćlise sobre eficiência em mercados futuros : uma comparação entre \\ os contratos de algodåo em pluma da BM\&F e da NYBOT / Fabiana \\ Salgueiro Perobelli. - - Piracicaba, 2001. \\ $76 \mathrm{p}$. \\ Dissertação (mestrado) - - Escola Superior de Agricultura Luiz de Queiroz, \\ 2001.
}

Bibliografia.

1. Algodão 2. Bolsa mercadorias 3. Comercialização agrícola 4. Eficiência econômica 5. Mercado futuro 6. Oferta e demanda l. Título

$\operatorname{CDD} 338.17351$

Permitida a cópia total ou parcial deste documento, desde que citada a fonte - $O$ autor 
“Navegar é preciso

Viver não é preciso" Fernando Pessoa 
Em certos momentos o chão pode até nos faltar, mas haverá aqueles que, estejamos certos ou não, nos apoiarão sempre.

À Deus, Irene, Natalino, Fernando e Fernanda. 


\section{AGRADECIMENTOS}

A CAPES pelo financiamento.

Ao professor Pedro Carvalho de Mello pela orientação e amizade.

Aos professores Geraldo Sant'Ana de Camargo Barros e Miriam R. P. Bacchi pela amizade, ajuda e sugestões oferecidas ao longo deste trabalho.

Ao professor Eduardo A Haddad pelo auxílio na fase final deste trabalho.

Aos professores e funcionários do Departamento de Economia Administração e Sociologia (DEAS) da ESALQ/USP, em especial à Maielli.

Aos amigos Ary e Marianne, presenças constantes.

Às amigas Juliana e Viviane pela amizade e convívio ao longo destes anos.

A Ana Lucia e Cristina pelo convívio.

A Cássia, Deborah e Juliana pela "paciência" na fase final.

Aos amigos Bruno, Daltro, Fábio e Róbson.

A Félix Schouchana pelas discussões e aprendizado sobre mercados futuros.

Ao Sérgio De Zen e Luiz Cláudio Caffagni pelo apoio durante o trabalho.

A Marcus Vinicius Menoita pela obtenção dos dados. 


\section{SUMÁRIO}

Página

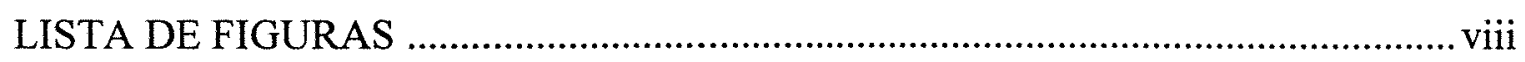

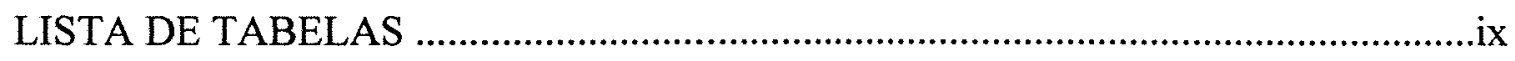

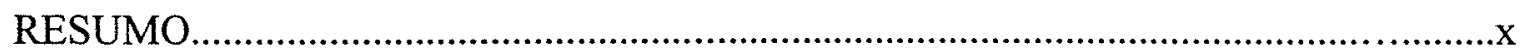

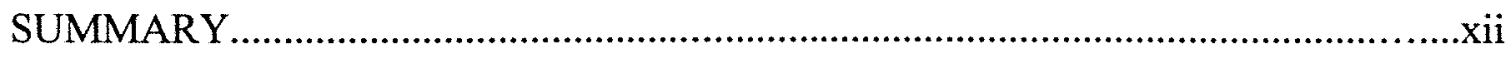

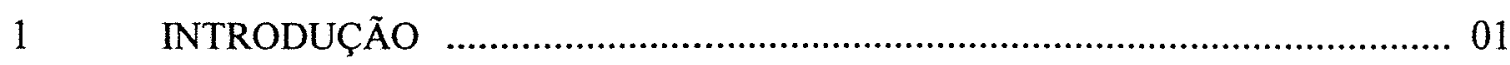

$1.1 \quad$ Relevância do Tema ..................................................................................... 03

1.2 Caracterização do Problema …………………............................................. 03

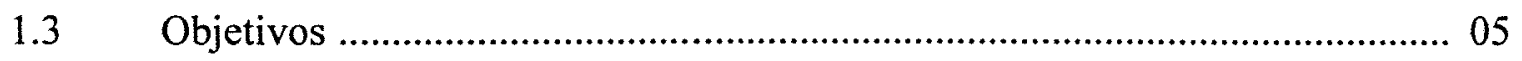

2 A COMERCIALIZAÇÃO DO ALGODÃO EM PLUMA ……………….... 06

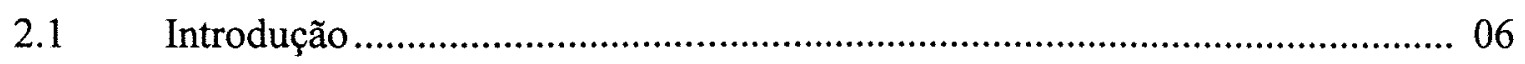

2.2 Oferta e demanda interna de algodão em pluma ………………………....... 06

$2.3 \quad$ O segmento agrícola ...................................................................................... 08

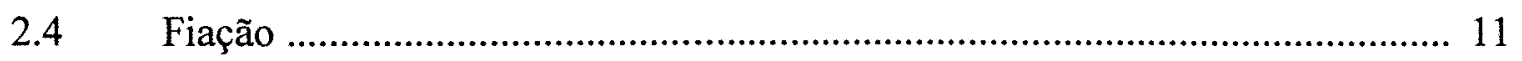

2.5 A comercialização do algodão em pluma................................................... 11

2.6 A intervenção governamental..................................................................... 13

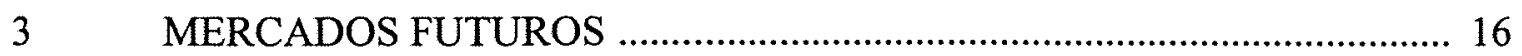

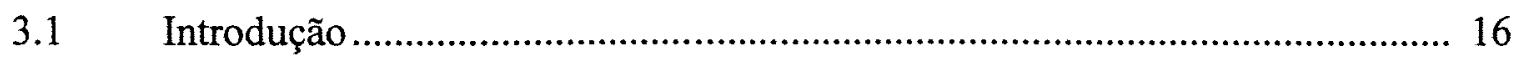

3.2 Abordagem característica da commodity ................................................. 18

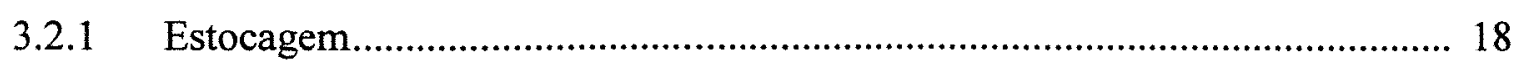

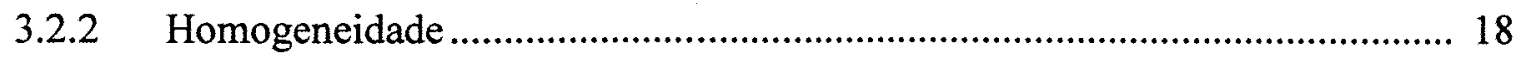

3.2.3 Volatilidade do preço............................................................................. 19

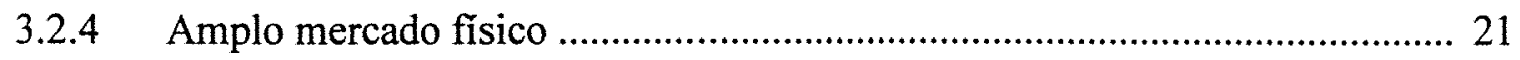




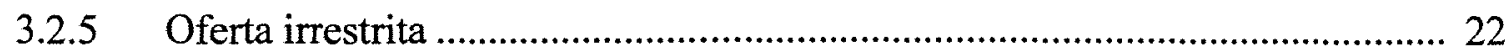

3.2.6 Efeitos do ambiente macroinstitucional ..................................................... 22

3.3 Abordagem desenho do contrato .............................................................. 23

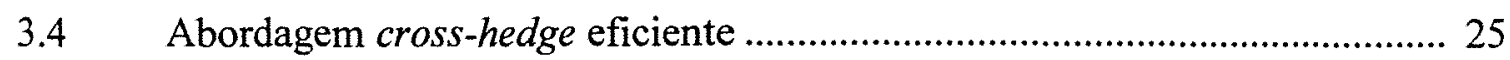

3.4.1 O modelo de Black .................................................................................... 26

4 EFICIÊNCIA EM MERCADOS FUTUROS ........................................... 29

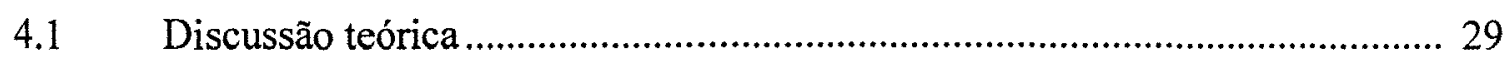

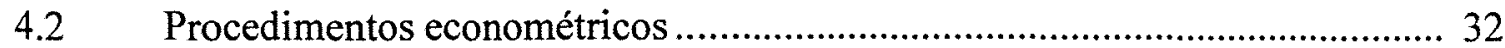

4.3 Justificativa para a utilização dos procedimentos econométricos no cálculo da eficiência de mercado ................................................................................ 36

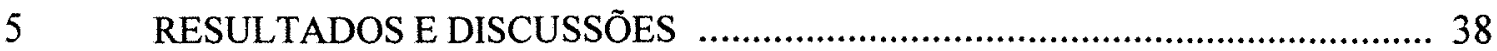

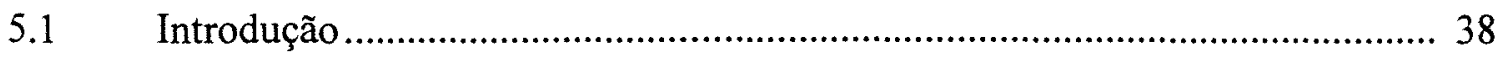

5.2 Procedimento de Engle \& Granger.................................................................... 39

5.3 Procedimento de Johansen........................................................................ 48

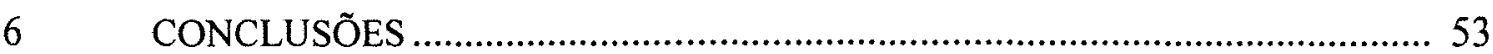

REFERÊNCIAS BIBLIOGRÁFICAS ………………............................... 56

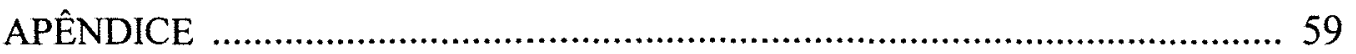




\section{LISTA DE TABELAS}

Página

1 Oferta e demanda brasileira de algodão em pluma (em mil toneladas)......... $\quad 8$

2 Produção por Estado (em mil toneladas - safras 93/94 a 99/00).................... 9

$3 \quad$ Volume de contratos negociados na BM\&F (1997-00)................................. 17

$4 \quad$ Volatilidade do preço à vista de commodities selecionadas (maio de $1998 \quad 21$

a janeiro de 2000)

5 Valores críticos tabelados para os parâmetros e resumo dos testes 42 implementados

$6 \quad$ Teste de raiz unitária para a série ESALQ …….............................................. 43

$7 \quad$ Teste de raiz unitária para a série NYBOT ………………........................... 44

$8 \quad$ Teste de raiz unitária para a série BM\&F .................................................... 45

$9 \quad$ Teste de cointegração para BM\&F e ESALQ.................................................. 47

10 Teste de cointegração para BM\&F e ESALQ ............................................... 48

$11 \quad$ Resultados do procedimento de Johansen.................................................... 50 


\section{LISTA DE FIGURAS}

Página

1 Fluxograma do Sistema Agroindustrial do Algodão (SAGA)

2 Evolução do Indicador ESALA/BM\&F e do $1^{\circ}$ vencimento do contrato futuro de algodão das bolsas BM\&F e NYBOT (1996 a 39 2000). 


\title{
ANÁLISE SOBRE EFICIÊNCIA EM MERCADOS FUTUROS: UMA COMPARAÇÃO ENTRE OS CONTRATOS DE ALGODÃO EM PLUMA DA BM\&F E DA NYBOT
}

\author{
Autora: FABIANA SALGUEIRO PEROBELLI \\ Orientador: Prof. Dr. PEDRO CARVALHO DE MELLO
}

\section{RESUMO}

A dissertação teve por objetivo analisar qual a opção de hedge era mais eficiente para os integrantes do Sistema Agroindustrial do Algodão, se era o contrato de algodão em pluma da Bolsa de Mercadorias \& Futuros (BM\&F) ou o da New York Board of Trade (NYBOT).

A escolha pela cadeia do algodão deveu-se ao fato deste setor ter passado na década de 1990 por substanciais mudanças que resultaram num sistema competitivo, tanto ao nível agrícola quanto industrial.

Além da reestruturação do setor a década de 1990 trouxe consigo algumas outras mudanças, como o início do processo de desregulamentação governamental do setor agrícola, fazendo com que os produtores passem a buscar instrumentos alternativos de gerenciamento de riscos que independam da participação do Estado. Outra mudança foi a permissão ao investidor estrangeiro para operar nos mercados futuros agropecuários brasileiros. 
Com este novo cenário poderia se esperar que estivessem criadas as bases para o desenvolvimento pleno do contrato futuro de algodão. $O$ instrumento de proteção natural para os agentes nacionais é o da BM\&F, pois se acredita que a utilização do contrato futuro de algodão da NYBOT não seja eficiente para estes agentes, devido às políticas de subsídios norte-americanas à produção de algodão e aos períodos distintos de safra e entressafra dos dois países.

As hipóteses anteriores foram comprovadas e verificou-se que durante o período analisado o contrato de algodão da BM\&F foi eficiente para o hedger nacional, no sentido que permitiu previsões não viesadas quanto ao futuro preço a vista no vencimento do contrato. Também concluiu-se que a opção norte-americana por hedge é arriscada para os agentes nacionais, sejam eles indústria ou produtor.

No que diz respeito ao fato do instrumento $B M \& F$ não estar sendo utilizado pelos agentes nacionais, a dissertação levantou algumas hipóteses. Dentre as quais estão a intervenção governamental no mercado de algodão, e o processo de integração verificado na cadeia como resultado da abertura econômica na década de 1990. Além do problema de capitalização encontrado por algumas empresas e produtores a fim de fazer frente ao pagamento de possíveis ajustes diários negativos no decorrer da operação de hedging. 


\title{
EFFICIENCY OF FUTURES MARKETS: A COMPARISON BETWEEN COTTON CONTRACTS OF BM\&F AND NYBOT
}

\author{
Author: FABIANA SALGUEIRO PEROBELLI \\ Adviser: Prof. Dr. PEDRO CARVALHO DE MELLO
}

SUMMARY

The present research has the aim of analyze which option of hedge could be more efficient for Brazilian members of cotton system, if it was the cotton contract of Brazilian Mercantile and Futures Markets (BM\&F) or the contract of New York Board of Trade (NYBOT).

The choice for studying the cotton system was that this sector lived important changes in last decade. That changes conduce to a more competitive system in all sectors: agricultural and industrial.

That changes implied in other results, like the beginning of government desregulamentation of agricultural sector. Now the producer has to find out another instruments of risk management, that it hasn't the government participation. Another change that occurs last decade was the liberation for foreign investor operates the brazilian agricultural futures markets.

With this new scenario would be expected that were created the bases for the development of the cotton futures markets. The natural instrument for manager the risk of price for Brazilian players was BM\&F. It believed that the instrument offered for 
NYBOT didn't will be efficient for that player, because of subsidies politics to USA cotton production and the distinct periods of production between the two countries.

The above hypothesis were correct and was verified that during the analyzed period the cotton contract of BM\&F were efficient for the Brazilian hedger, in the way that were possible to preview the future real price in the date of expiring the contract. Another conclusion was that the cotton contract offered by NYBOT was a risk option for Brazilian hedgers.

The present research made some considerations about the fact of the instrument offered by BM\&F was not been in use by Brazilian players. Some hypothesis consider the government intervention in the cotton market, the process of integration verified in this sector results from open economics process started in last decade. 


\section{INTRODUÇÃO}

O Sistema Agroindustrial do Algodão (SAG-A) tem passado nos últimos anos, em toda a sua extensão, por um processo ímpar de reestruturação, resultado da política de abertura comercial implementada no começo da década de 1990. Tal processo implicou em ações por parte dos agentes objetivando torná-los competitivos, diante do avanço da concorrência com os produtos importados.

Uma característica marcante deste setor foi a existência, até o início da década de 1990, de um protecionismo de mercado, tanto ao nivel agrícola quanto industrial, em relação aos produtos importados, e que resultou em ciclos descontínuos (esporádicos) de investimento. Assim quando da abertura comercial, o SAG-A encontrava-se defasado tecnologicamente e sem condições de competitividade com aqueles produtos.

A importância deste setor para a economia brasileira sempre foi evidente, quer pelo nível de emprego gerado, pela participação no Produto Interno Bruto (PIB) ou ainda, devido a sua influência na balança comercial. No entanto, desde o final da década de 1980 tal relevância se deteriorava, e o setor perdia espaço no cenário nacional, como na produção de algodão em que o País passou de exportador a importador da fibra.

A reestruturação do setor já se encontra em processo avançado, sendo possivel notar algumas mudanças. Na parte agrícola do SAG-A, verifica-se a transição do modelo "tradicional" (pequena propriedade, intensivo em mão-de-obra) para o "empresarial" (grande propriedade, mecanizada). $O$ segmento industrial avançou para um sistema caracterizado por um número menor de empresas, integração (fiação/tecelagem/confecção), e intensivo uso de capital.

$O$ processo de reestruturação do SAG-A o tem conduzido a um sistema competitivo e integrado com a nova perspectiva mundial: a de mercados interligados. A 
idéia da globalização é a da inexistência de barreiras, tanto para a entrada de produtos quanto de capitais. Assim, neste novo cenário ganha importância a negociação em mercados futuros, posto que tais contratos passaram a ter notoriedade nas últimas décadas com a explosão de eventos na economia que deram uma maior volatilidade aos preços e taxas de juro, resultando num ambiente de incertezas quando da tomada de decisão (Leuthold et al, 1989).

No caso brasileiro, torna-se fundamental o bom funcionamento dos mercados futuros, principalmente dos contratos agropecuários, em função da desintermediação governamental no setor. Sendo assim, faz-se necessário aos produtores o uso de instrumentos de gerenciamento de risco que independam da participação do Estado (Martits, 1998).

Acredita-se que alguns eventos podem contribuir para a consolidação deste cenário, dentre eles estão: o processo de desintermediação governamental do setor agrícola e o fim das medidas restritivas que impediam os investidores estrangeiros a operar nos mercados futuros agropecuários brasileiros. Segundo Moraes (1999) "com a perspectiva de dinamização dos negócios, os produtores, as cooperativas, os comerciantes, as indústrias e os exportadores terão melhores condições para operar, dando liquidez ao mercado e maior segurança para a realização de contratos de médio prazo".

As maiores bolsas estão nos Estados Unidos, a Chicago Board of Trade (CBOT) e a Chicago Mercantile Exchange (CME). Entretanto, deve ser notado um fato marcante salientado por Leuthold (1994) apud Souza (1998): a partir de 1993, o volume negociado fora dos Estados Unidos passou a ser igual ao interno. Além disso, é cada vez maior a diversidade de contratos negociados por estas bolsas. No Brasil, a bolsa de futuros em atividade é a Bolsa de Mercadorias \& Futuros (BM\&F), que negocia tanto ativos financeiros quanto agropecuários. A participação destes no total negociado ainda é pequena: em 2000 o setor respondia por $0,93 \%$ do total.

Quanto ao mercado futuro de algodão pode-se dizer que nunca foi capaz de acompanhar a dinâmica do setor, tendo apenas seu período áureo de 1920 a 1956. Depois 
entrou em declínio tendo uma ligeira recuperação no final da década de 1970 (Martits, 1998). O contrato foi relançado pela BM\&F no final de 1996, e alterado em 1999 , quando da internacionalização dos contratos agropecuários.

Deve-se ressaltar que o mercado futuro de algodão sempre foi marcado, ao longo de sua história, por constantes intervenções governamentais que prejudicaram seu desempenho. No entanto, tem-se agora uma perspectiva de saída do governo, de não intervenção na comercialização e no setor produtivo (produtor e usuário da fibra de algodão), liberação para a participação de investidores estrangeiros neste mercado e da reestruturação produtiva do SAG-A em bases competitivas.

\subsection{Relevância do Tema}

A importância crescente dos mercados futuros pode ser evidenciada pelo aumento no volume de contratos negociados pelas maiores bolsas mundiais, atraindo desta forma um crescente interesse do público. Como exemplo tem-se a Chicago Board of Trade que negociou 120.769.789 contratos em 1990, passando a 189.662.407 em 2000 .

A relevância deste estudo está na percepção de um novo cenário, que abrange a globalização dos mercados e a entrada de investidores estrangeiros, que podem afetar de forma positiva o desenvolvimento dos mercados futuros agropecuários no Brasil, transformando-os em instrumentos eficientes para o gerenciamento de riscos. A escolha pelo algodão deve-se ao fato do setor ter passado na década de 1990 por um processo de reestruturação que o está conduzindo a um patamar de competitividade, tanto em nível agrícola quanto industrial. Ademais, a literatura sobre mercados futuros agropecuários no Brasil ainda é pequena, especialmente sobre algodão.

\subsection{Caracterização do Problema}

O contrato futuro de algodão passou a ser negociado em 1918 através da Bolsa de Mercadorias de São Paulo (BMSP). Foi o único, de um conjunto de ativos agropecuários (milho, açúcar, arroz, feijão e mamona), que obteve sucesso até a segunda 
guerra mundial, segundo Souza (1998, p. 10), devido à especialização da bolsa nesta atividade. As décadas seguintes foram de declínio até a sua paralisação. A retomada da negociação só se deu no final de 1996, quando houve o relançamento do contrato pela $\mathrm{BM} \& \mathrm{~F}$.

A retração deste contrato é atribuída, segundo Santos Filho (1982) apud Souza (1998), à política de subsídio americana à produção de algodão e à política interna de preços mínimos. As politicas públicas sempre foram um fator que influenciaram o desenvolvimento do mercado futuro de algodão.

Há o estabelecimento, como já ressaltado, de um novo cenário capaz de alterar positivamente o mercado futuro de algodão, cuja base está no processo da globalização que exigiu a abertura comercial implicando na reestruturação da cotonicultura, levando à falência o sistema produtivo anterior. Há também o processo de desintermediação governamental e a liberação para $o$ investidor estrangeiro fazer uso do mercado brasileiro.

Com este novo cenário poderia se esperar que estivessem criadas as bases para o desenvolvimento pleno do contrato futuro de algodão, para que este cumpra uma de suas principais funções: a de servir como um instrumento de gerenciamento de risco aos produtores de algodão e às indústrias de fiação. $\mathrm{O}$ instrumento de proteção natural para os agentes nacionais é o da $\mathrm{BM} \& \mathrm{~F}$, pois se acredita que a utilização do contrato futuro de algodão oferecido pela New York Board of Trade (NYBOT) não seja eficiente para estes agentes, devido às políticas de subsídio norte-americanas à produção de algodão e aos períodos distintos de safra e entressafra dos dois países. Entretanto, há algumas características na comercialização do algodão que têm prejudicado o desenvolvimento do mercado futuro de algodão no Brasil. 


\subsection{Objetivos}

O objetivo desta dissertação é o de avaliar qual é o melhor instrumento de hedge ${ }^{1}$ para os agentes do mercado brasileiro de algodão em pluma. As duas opções a serem testadas são o contrato futuro de algodão da BM\&F, relançado em 1996 e o da NYBOT.

O trabalho além desta parte introdutória, apresenta em seu segundo capítulo uma caracterização da comercialização do algodão em pluma. No terceiro capitulo é apresentada uma evolução teórica sobre os determinantes para o desenvolvimento de um contrato futuro. Assim, a análise conjunta dos capítulos 2 e 3 permitirão elucidar alguns fatores que poderiam estar delimitando o desenvolvimento do contrato em análise.

O capítulo 4 traz uma discussão teórica sobre o conceito de eficiência em mercados futuros, e no capítulo 5 são apresentados os resultados para os testes implementados a fim de verificar qual foi, no período em análise, o melhor instrumento de hedge para o agente nacional, se o da BM\&F ou da NYBOT.

\footnotetext{
${ }^{1}$ Hedge é uma operação realizada em mercados futuros que tem por objetivo proteger uma determinada posição assumida no mercado a vista, seja ela de venda de um produto (Hedge de venda), ou a aquisição de uma mercadoria (Hedge de compra).
} 


\section{A COMERCIALIZAÇÃo DO ALGODÃO EM PLUMA}

\subsection{Introdução}

Será analisado, neste capítulo, o processo de comercialização do algodão em pluma, a fim de verificar, na cadeia, quais agentes estariam sujeitos ao risco de oscilação dos preços do produto. A importância de tal apreciação deve-se também à possibilidade de elucidar alguns fatores que estariam limitando o desenvolvimento do contrato futuro de algodão da BM\&F, e deixando aqueles agentes "órfãos" de um instrumento de seguro de preços. Neste sentido se justifica um tópico discutindo o processo de intervenção governamental na comercialização do algodão.

O Sistema Agroindustrial (SAG) ${ }^{2}$ do Algodão está representado na figura 1. O algodão em caroço produzido nas propriedades rurais é transformado em pluma nas algodoeiras, passando a fio nas fiações, em tecido cru na tecelagem, em estampado na tinturaria e acabamento, em roupas e outros produtos como lençóis nas confecções, e finalmente são distribuídos pela indústria varejista. (Urban et al, 1995, p. 14)

De acordo com a figura 1, percebe-se que a comercialização do algodão em pluma envolve as algodoeiras, que transformam o caroço de algodão em pluma através do beneficiamento, realizado em regime de parceria ou não. Ao final deste processo vendem a pluma às fiações.

\subsection{Oferta e demanda interna de algodão em pluma}

A análise do quadro de oferta e demanda interna do algodão em pluma permite verificar o grau de auto-suficiência da produção nacional. É possível observar que grande

\footnotetext{
${ }^{2}$ O conceito de SAG, segundo Michellon (1999, p. 48), assemelha-se ao de agribusiness, e engloba todos os participantes do sistema agroalimentar e de fibras desde o fornecedor de insumos ao produtor agricola, processador, distribuidor até o consumidor final.
} 
parte da década de 1990 foi marcada pela perda de dinamismo da produção nacional e expansão das importações. A safra 1997/98 marcou uma reversão da trajetória anterior e desde então houve avanços da produção capazes de reduzir a quantidade importada. $O$ consumo neste período tem sido crescente. Para a safra 2000/01 nota-se a autosuficiência da produção, permitindo a geração de excedentes exportáveis. (Tabela 1).

INSUMOS (PRÉ-PORTEIRA)

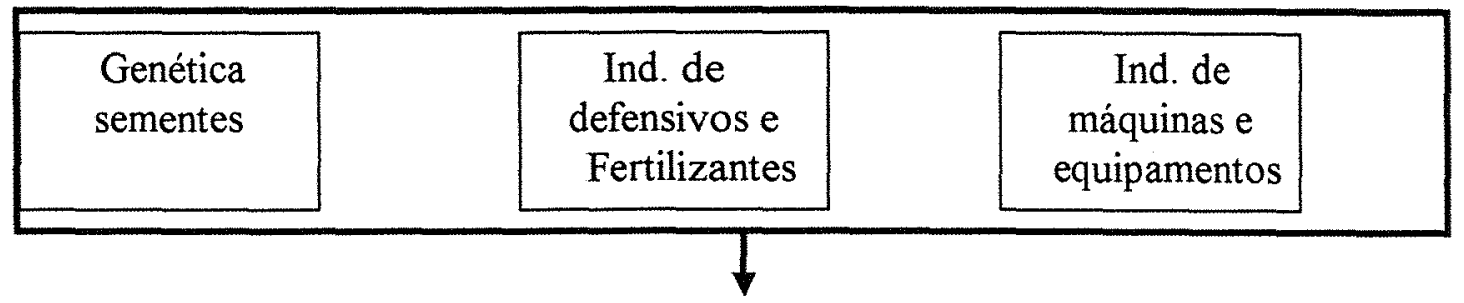

COTONICULTURA (algodão em caroço)

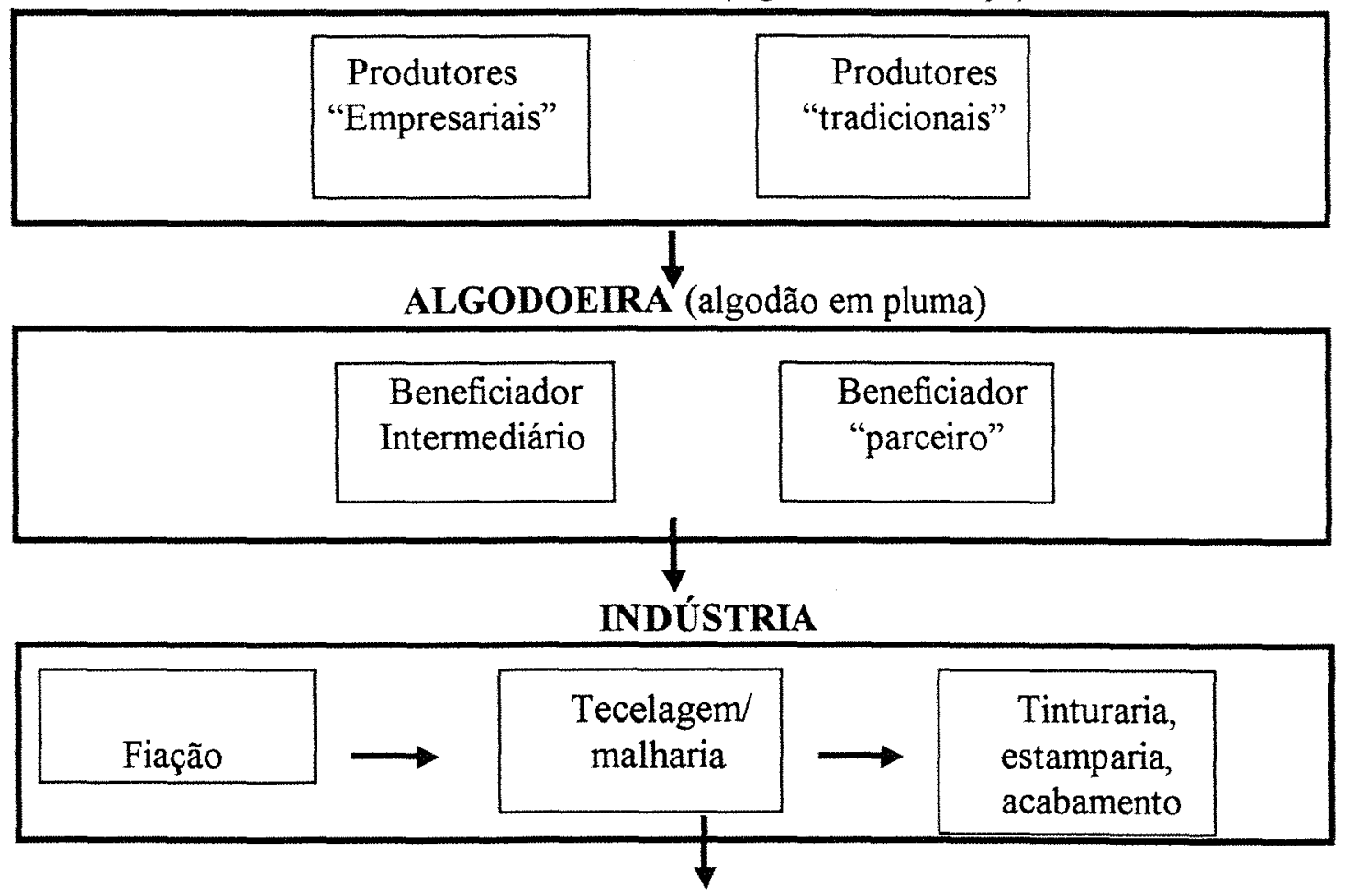

\section{CLIENTES DA INDÚSTRIA}

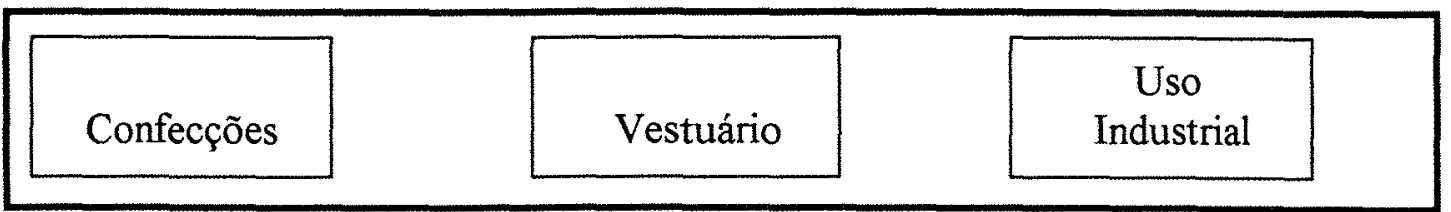

Fonte: Jayo \& Nunes (1998, p. 269)

Figura 1 - Fluxograma do Sistema Agroindustrial do Algodão (SAG-A) 
Tabela 1. Oferta e demanda brasileira de algodão em pluma (em mil toneladas).

\begin{tabular}{l|rrrrr}
\hline & Produção & Importação & Consumo & Exportação & Estoque Final \\
\hline $90 / 91$ & 717,0 & 105,9 & 718,1 & 124,3 & 16,9 \\
$91 / 92$ & 667,1 & 167,8 & 741,6 & 33,8 & 76,4 \\
$92 / 93$ & 420,2 & 501,2 & 829,5 & 7,4 & 160,9 \\
$93 / 94$ & 483,1 & 367,3 & 836,6 & 4,3 & 170,4 \\
$94 / 95$ & 537,0 & 284,3 & 803,7 & 52,5 & 135,5 \\
$95 / 96$ & 410,1 & 472,0 & 829,1 & 1,6 & 186,9 \\
$96 / 97$ & 305,7 & 438,5 & 798,7 & 0,3 & 132,1 \\
$97 / 98$ & 411,0 & 334,4 & 782,9 & 3,1 & 91,5 \\
$98 / 99$ & 520,1 & 280,3 & 849,5 & 3,9 & 38,5 \\
$99 / 00$ & 700,3 & 270,0 & 900,0 & 15,0 & 93,8 \\
$00 / 01$ & 861,8 & 190,0 & 930,0 & 120,0 & 100,6 \\
\hline
\end{tabular}

Fonte: Conab (Relatório março de 2001)

Dentre os fatores que levaram o País à condição de importador de algodão estão a redução das alíquotas de importação, elevação dos prazos de pagamento para 180 a 360 dias $^{3}$, diferenças das taxas de juro interna e externa e existência de subsídios na origem, como nos Estados Unidos. (Jayo \& Nunes, 1998)

O grande demandante do algodão é a indústria têxtil, que também sofreu com a concorrência de produtos importados em função do processo de abertura. Hoje esta indústria se encontra num estágio avançado de reestruturação, podendo estar contribuindo para estimular as expansões da produção de algodão em pluma.

\subsection{O segmento agrícola}

A distribuição regional da estrutura produtiva do algodão em pluma no Brasil passou por importantes transformações na década de 1990. Pode-se perceber uma inversão de papéis entre a região Sul/Sudeste e o Centro-Oeste. A primeira vem 
perdendo participação no total produzido em detrimento do aumento de produção no Centro-Oeste. No que tange ao Norte/Nordeste há uma recuperação no fim do período, sendo este proporcionado, em grande parte, pela produção dos estados da Bahia e Ceará.

Tabela 2. Produção por Estado (em mil toneladas - safras 93/94 a 99/00)

\begin{tabular}{|c|c|c|c|c|c|c|c|}
\hline Estados & $93 / 94$ & $94 / 95$ & $95 / 96$ & $96 / 97$ & $97 / 98$ & $98 / 99$ & $99 / 00$ \\
\hline Rondônia & 11,9 & 9,8 & 5,3 & 2,3 & 1,8 & 1,1 & 0,2 \\
\hline Pará & 1,0 & 1,1 & 1,1 & 0,4 & 0,4 & 0,4 & 0,4 \\
\hline Maranhão & 0,6 & - & - & - & - & - & - \\
\hline Piauí & 13,1 & 13,5 & 9,3 & 5,8 & 0,6 & 1,6 & 2,2 \\
\hline Ceará & 27,3 & 12,9 & 12,6 & 6,3 & 5,8 & 14,6 & 26,7 \\
\hline Rio Grande Norte & 9,7 & 5,3 & 9,1 & 5,4 & 0,6 & 1,2 & 5,0 \\
\hline Paraíba & 6,2 & 7,4 & 7,5 & 5,9 & 0,8 & 2,4 & 9,9 \\
\hline Pernambuco & 1,9 & 3,7 & 2,9 & 2,1 & 0,4 & 0,4 & 1,6 \\
\hline Alagoas & 4,3 & 1,0 & 1,7 & 1,9 & 1,4 & 0,7 & 1,5 \\
\hline Sergipe & 0,9 & 0,5 & 0,3 & 0,5 & 0,1 & 0,1 & 0,1 \\
\hline Bahia & 45,3 & 32,4 & 26,6 & 28,5 & 13,2 & 14,8 & 41,6 \\
\hline Norte/Nordeste & 122,2 & 87,6 & 76,4 & 59,1 & 25,1 & $\mathbf{3 7 , 3}$ & 93,2 \\
\hline Minas Gerais & 26,3 & 27,0 & 23,1 & 28,1 & 41,1 & 28,9 & 38,7 \\
\hline São Paulo & 83,3 & 111,2 & 63,4 & 54,4 & 66,9 & 53,2 & 55,2 \\
\hline Paraná & 146,3 & 175,7 & 119,5 & 40,3 & 64,5 & 38,8 & 43,0 \\
\hline Sul/Sudeste & 255,9 & 313,9 & 206,0 & 122,8 & 172,5 & 120,9 & 136,9 \\
\hline Mato Grosso & 41,5 & 38,9 & 33,1 & 34,8 & 94,2 & 226,4 & 335,8 \\
\hline Mato G. Sul & 28,0 & 44,8 & 35,7 & 19,6 & 32,6 & 42,9 & 43,8 \\
\hline Goiás & 33,5 & 51,9 & 58,8 & 69,4 & 86,6 & 92,6 & 89,8 \\
\hline Distrito Federal & - & - & - & - & - & - & 0,8 \\
\hline Centro-Oeste & 105,0 & 135,6 & 127,6 & 123,8 & 213,4 & 361,9 & 470,2 \\
\hline BRASIL & 483,1 & 537,1 & 410,0 & 305,8 & 411,0 & 520,1 & 700,3 \\
\hline
\end{tabular}

Fonte: Conab (Relatório março de 2001)

A cotonicultura representa a atividade de cultivo do algodoeiro, que podem ser de dois tipos: arbóreo e herbáceo. O arbóreo é encontrado quase exclusivamente no Nordeste, caracteriza-se por ser perene ${ }^{4}$ e apresentar fibras mais longas (entre 34 e 36 mm). Hoje não apresenta importância comercial, pois sua fibra é de baixo valor

\footnotetext{
${ }^{3} \mathrm{O}$ que normalmente se verificavam eram 10 dias.

${ }^{4}$ Permite várias colheitas anuais da mesma planta.
} 
econômico e de baixa produtividade, além disso, sua produção sofreu em meados da década de 1980 grande recuo devido à praga do "bicudo do algodoeiro".

Tal fato implicou na mudança de perfil da cotonicultura nacional, ganhando importância a produção tipo herbácea predominante no Centro-Sul do País, de cultivo anual, com plantio em setembro e outubro e colheita em março e abril.

A cotonicultura do Centro-Sul do País era pulverizada, caracterizada por uma unidade típica de exploração pequena, pouco tecnificada, gerida em regimes de parceria e arrendamento, e baixos investimentos na lavoura. Nas décadas de 1930 a 1980 observouse alternância entre São Paulo e Paraná, na posição de maior produtor.

Nos anos 90 surge a "cotonicultura empresarial", em contraste ao modelo tradicional. Representa uma mudança de perfil, posto que se caracteriza por grandes extensões de terra, estrutura concentrada, mecanizada, maior produtividade, devido à busca constante pelo desenvolvimento de variedades mais resistentes a pragas, e custos elevados, em torno de US\$1.300/hectare ${ }^{5}$. Os produtores não são exclusivos do algodão. Normalmente, tal atividade está conjugada à da soja e milho.

A produção no Centro-Oeste está concentrada principalmente no Mato Grosso, na região de Primavera do Leste e Rondonópolis, mas há tendência de desenvolvimento da cultura para o Norte do estado, próximos a Sapezal e Campo Verde; regiões que possuem custos de produção menores devido às condições climáticas e por possuirem solos novos, que não sofreram a incidência de defensivos utilizados em outras culturas.

$\mathrm{Na}$ "cotonicultura empresarial" prevalece o processo de colheita mecanizada da produção. Os produtores, em sua maioria, possuem colheitadeiras ${ }^{6}$, e que são de uso exclusivo. Por ser uma atividade intensiva em tecnologia, mecanizada e exigir tratos culturais maiores se comparada a outras culturas é uma atividade de risco elevado. O empresário precisará de investimentos consideráveis para entrar e se manter na atividade o que implicará de certa forma na constituição de barreiras à entrada e à saída, caracterizando então por ser uma atividade de baixa rotatividade dos agentes.

\footnotetext{
${ }^{5}$ Como exemplo tem-se a soja cujos custos estão em torno de US\$ 300 a 500 por hectare.

${ }^{6}$ Em torno de US\$ 250 mil.
} 


\subsection{Fiação}

O setor passou por um processo de enxugamento no número de empresas. Em 1995 eram 661 empresas das quais 475 localizavam-se na região Sudeste ( $72 \%$ do total). O maior produtor é o estado de São Paulo com 343 empresas, o Nordeste está em segundo lugar com 102 empresas. No entanto, há nos últimos anos uma reversão deste quadro, com muitas empresas se deslocando especialmente para o Ceará (que em 1995 já se constituía o segundo maior produtor de fios, atrás de São Paulo e seguido por Santa Catarina e Minas Gerais), devido aos incentivos fiscais e creditícios oferecidos, além da mão-de-obra mais barata.

Uma característica comum na fiação é a integração de empresas, pois a implantação de uma unidade de fiação economicamente viável só é possivel a partir de grandes volumes de produção, já que os equipamentos exigidos possuem escalas mínimas de produção elevadas e trabalham de forma interligada, em regime contínuo.

$O$ processo de abertura atingiu principalmente as empresas não integradas, com uma queda de $50 \%$ no número de empresas. Quanto à capacidade instalada não houve alteração do quadro, devido ao aumento de produção do Nordeste (única região a se expandir durante a crise). No parque de máquinas instaladas não houve alteração refletindo uma concentração maior, decorrente da necessidade de escala no segmento.

Dentre as mudanças observadas houve queda da idade média dos filatórios a rotor e a anel, indicando o esforço da indústria nacional para alcançar um grau de modernização compativel com os parâmetros internacionais. As empresas integradas desde a fiação e tecelagem até o acabamento redirecionaram o mix de produtos para tecidos de maior valor agregado e rentabilidade. O número de empregos reduziu-se seguindo a tendência de modernização do parque e maior concentração produtiva.

\subsection{A comercialização do algodão em pluma}

Neste tópico serão analisadas as características da comercialização do algodão em pluma feita entre os produtores da chamada "cotonicultura empresarial" e as fiações de Santa Catarina, Minas Gerais e Ceará. Tal restrição geográfica é função de se acreditar 
que o modelo de produção adotado pela "cotonicultura empresarial" será o que irá prevalecer $^{7}$ no SAG-A nos próximos anos.

A opção de comercialização mais utilizada pelos produtores tem sido a venda antecipada. A negociação ocorre normalmente no momento do plantio e realiza-se de duas formas: com um preço fixo ou a fixar. No preço fixo, depois de fechado o contrato, eventuais variações de preço não serão captadas, causando assim incertezas quanto ao cumprimento do acordo pelas partes. $\mathrm{Na}$ modalidade preço a fixar, garante-se o comprador para o produto, mas como a liquidação é feita através do preço do mercado do dia, utilizando em muitos casos o Indicador de Preços do Algodão em Pluma ESALQ/BM\&F, o produtor estará totalmente vulnerável às oscilações de preço, estando desta forma exposto ao risco.

A relação entre fiações e produtores parece próxima, sem receio de eventuais quebras contratuais pelas partes. No entanto, não é estável, pois não há garantias de cumprimento do contrato, ou punições em caso contrário. Há neste ponto um espaço para o desenvolvimento dos mercados futuros. Estes produtores não são exclusivos de algodão mantendo atividades como soja e milho, e fazem a venda ou estocagem do produto que melhores condições de mercado encontrar no momento da venda, havendo então demanda por hedge.

A não utilização dos mercados futuros como opção de comercialização, se deve, segundo os produtores à ausência de agentes na ponta compradora. Para estes o mercado futuro só se desenvolverá quando os compradores passarem a atuar na Bolsa, dando liquidez às negociações. Dentre outros fatores elencados para a não utilização estão a baixa liquidez, as margens de garantia e a necessidade de um montante monetário para cobrir os eventuais ajustes diários negativos.

As fiações adquirem a pluma no mercado, não tendo atividades de plantio ou beneficiamento do caroço. A maioria faz integração para frente tendo como produtos

\footnotetext{
7 A caracterização das transações entre produtores e fiações está baseada no trabalho de Ferreira Filho, J.B.S. \& De Zen, S. (1998) sobre a comercialização do algodão em pluma. Os resultados aqui apresentados referem-se aos questionários aplicados aos agentes da comercialização (fiação, produtores e corretores) para identificar como esta se processa.
} 
finais desde o fio (para as não integradas) até artigos de cama, mesa, banho, roupas e tecidos. Outra característica comum diz respeito ao período de manutenção de estoques, não superior a 30 dias. As fiações têm corretores para a compra do algodão, em função da confiança junto aos corretores quanto ao recebimento e à qualidade do produto.

A comercialização é feita de três formas: através de contrato de fornecimento junto a uma empresa determinada, no mercado spot ou via importações. A opção pelo algodão brasileiro tem sido para não manter estoques. No caso do Ceará as importações normalmente são mais lucrativas se comparadas à aquisição do algodão de Mato Grosso, devido aos custos de frete e tributários, especialmente ICMS.

Dentre os motivos para a não utilização do mecanismo de mercados futuros estão a declaração de desconhecimento de algumas fiações, tendo como justificativa a falta de orientação por parte das corretoras e a falta de um departamento financeiro interno. Já outras fiações não utilizam o mercado futuro em função da falta de liquidez interna.

Com relação à ponta compradora seriam necessários alguns estudos mais detalhados a fim de comprovar algumas hipóteses, dentre as quais, o comprador do algodão em pluma, no caso as fiações, não utilizam o instrumento por possuírem um instrumento de hedge natural. Neste caso hedge natural está atrelado à idéia da empresa ser capaz de repassar qualquer variação no custo para o preço de venda. No caso das

fiações, isto parece provável, pois as mesmas não concorrem no mesmo nicho de mercado. Assim qualquer que seja o preço de aquisição da pluma, as fiações poderão repassar no produto final, que para algumas serão produtos de cama, mesa, banho, jeans, tecidos. Assim, estariam hedgeadas naturalmente.

\subsection{A intervenção governamental}

$O$ processo de desenvolvimento econômico brasileiro foi marcado pela participação do governo de forma ativa no processo produtivo através da manutenção de empresas estatais e também por políticas que visavam regular os mercados. Quando da abertura comercial nos anos 90 foi possível notar o quão ineficiente fora o processo regulatório, e o que se observou foi, especialmente no caso do setor têxtil, uma 
ineficiência dos agentes. Tal ineficiência era função da falta de iniciativa dos agentes dado que o governo sempre regulou a economia. Da forma como o processo de abertura foi conduzido levou ao fechamento de muitas empresas, pois tiveram que concorrer com a indústria internacional mais eficiente.

Assim, o governo sempre foi ativo na produção e comercialização. Após os anos 80 quando a divida pública - interna e externa, atingiu valores constrangedores passou-se a verificar um processo de saída do governo do processo produtivo. No entanto, continua tendo participação ativa na comercialização - com a política de garantia dos preços mínimos.

Martignon \& De Zen (2000) fizeram uma análise sobre o processo de intervenção governamental na comercialização do algodão.

"O governo passou a participar de forma ativa no processo, adquirindo o produto e passando a carregar os estoques. Neste processo mostrou que não era especialista na atividade comercial e modificou a sua forma de atuação, passando a oferecer um mecanismo pelo qual a produção é comercializada sem a intervenção direta. $O$ processo utilizado foi a oferta de um prêmio que visa recompor o preço de mercado de maneira que esse fique no patamar do preço mínimo. A utilização desse instrumento significou um consistente avanço no processo de intervenção do estado, mas ainda assim demanda recursos do tesouro"

Em 17 de abril de 1998 o algodão foi incluído no Programa de Escoamento da Produção (PEP). Neste o governo fornece um prêmio capaz de equalizar o preço mínimo, sem arcar com custos de estocagem e transporte. Em termos de resultados o trabalho de Martignon \& De Zen (2000) mostrou que o programa não foi capaz de elevar os preços do algodão, que durante as intervenções governamentais se comportaram próximos ao preço mínimo. Assim, a comercialização do algodão estava sendo feita via leilões do governo e quando realizadas no mercado fisico as fiações tinham um importante poder de barganha junto aos produtores, e assim, os preços se comportaram 
em queda. O importante desta análise é ressaltar que as intervenções do governo foram dispendiosas e não cumpriram com o objetivo de impedir a queda de preços na safra - e o que se verificou foi que o governo ao intervir na economia impediu as oscilações de preço, no sentido que assumiu o risco da comercialização.

Foi possível notar ao longo deste capítulo a dinamização ocorrida na década de 1990 no SAG do algodão, proporcionada pelo processo de abertura comercial. Tal dinamização implicou não somente em eficiência produtiva mas também em mudanças nas relações comerciais. $O$ processo de fusões foi uma característica das transformações ocorridas, assim novos instrumentos são necessários para viabilizar e tornar eficiente a comercialização da pluma.

Há neste sentido espaço para instrumentos que possibilitem o seguro do risco de preço, como é o caso dos mercados futuros, já que a comercialização é órfã de um instrumento como este, pois realiza operações de preço a fixar, no qual as duas pontas estão abertas ao risco. Assim, as mudanças ocorridas na década de 90 implicaram não somente na dinamização do setor mas também na disponibilização de instrumentos eficazes a fim de auxiliar os agentes no processo de comercialização. 


\section{MERCADOS FUTUROS}

\subsection{Introdução}

O objetivo deste capitulo é o de justificar algumas características encontradas ao se analisar a estrutura do mercado físico de algodão em pluma e que foram avaliadas como sendo delimitadoras do desenvolvimento do mercado futuro daquele produto. Assim, poderá ser visto neste capítulo uma rápida explicação teórica dos modelos que foram desenvolvidos a fim de justificar os elementos que poderiam estar impedindo ou não o desenvolvimento daquele instrumento.

A negociação de commodities em mercados futuros iniciou-se em 1865, nos Estados Unidos, através da Chicago Board of Trade (CBOT). Apesar da negociação em mercados futuros ser secular, estes contratos só passaram a ter notoriedade nas últimas décadas com a ocorrência de eventos no mundo econômico que deram uma maior volatilidade aos preços e taxas de juro, resultando assim, num ambiente de incertezas quando da tomada de decisão (Leuthold et al, 1989).

A justificativa para a maior atenção a estes mercados deve-se, segundo Tsetsekos \& Varangis (1997, p.3), ao crescimento explosivo dos derivativos nos últimos dez anos, levando as negociações a niveis que excedem 20 trilhões de dólares.

No caso brasileiro a maior bolsa de futuros em atividade é a Bolsa de Mercadorias $\&$ Futuros (BM\&F) ${ }^{8}$, que transaciona ativos diversificados, atuando nos mercados de futuros financeiros, onde se encontram os ativos de maior destaque: Taxas de juro $(60,71 \%)$ e Taxa de câmbio $(28,49 \%)$, e nos mercados agropecuários, que mantêm ainda uma participação pouco expressiva $(0,93 \%)$, como pode ser notado pela Tabela 3 . Deve 
ser ressaltado que, em termos relativos, os ativos agropecuários têm aumentado sua participação que era de 0,13\% em 1996 passando a 0,93\% em 2000.

A BM\&F negocia os seguintes contratos agrícolas: açúcar cristal, algodão, boi gordo, café arábica, milho e soja. Os que apresentaram melhor desempenho no ano de 2000 foram café arábica $(59,34 \%)$ e boi gordo $(22,86 \%)$, enquanto o algodão teve uma modesta participação (menos de 0,1\%). E, em 31 de março de 2000 tiveram início as negociações do contrato de álcool anidro.

Tabela 3. Volume de contratos negociados na BM\&F (1997-00)

\begin{tabular}{l|rrrrr}
\hline \multicolumn{1}{c|}{ Ativos } & \multicolumn{1}{c}{1997} & \multicolumn{1}{c}{1998} & \multicolumn{1}{c}{1999} & \multicolumn{1}{c}{2000} & $\%{ }^{*}$ \\
\hline Taxa de câmbio & 48572750 & 22065476 & 12166257 & 20208454 & 28,49 \\
Índice de ações & 15306509 & 10033560 & 5578148 & 7000335 & 9,87 \\
Taxas de juros & 37301363 & 39098345 & 25292621 & 43063873 & 60,71 \\
Títulos da dívida & 300818 & 7284 & 2720 & 2600 & 0,003 \\
Agropecuários & 285648 & 382662 & $\mathbf{5 5 1 7 3 4}$ & 658085 & 0,93 \\
Total & $\mathbf{1 2 2} \mathbf{1 7 9 3 9 3}$ & $\mathbf{7 1 ~ 9 4 2 ~ 2 7 4}$ & $\mathbf{4 4 0 5 6 0 6 7}$ & $\mathbf{7 0 9 3 3 3 4 7}$ & $\mathbf{1 0 0}$ \\
\hline
\end{tabular}

Fonte: Resenha BM\&F(janeiro-fevereiro, 2001)

*Participação dos ativos em relação ao total, referente ao ano de 2000.

Devido à sua importância crescente os mercados futuros têm sido durante décadas alvo de inúmeras pesquisas que almejam entender por que alguns produtos são transacionados e outros não. A literatura a respeito do assunto tem se baseado na análise de casos específicos para encontrar respostas para a questão; isto é, verificar por que determinadas inovações contratuais falharam ou não. Distingue-se na literatura existente duas abordagens sobre o sucesso de inovações contratuais: a) características da commodity e b) características do desenho do contrato.

A primeira abordagem leva em consideração uma lista de atributos que as commodities devem possuir para serem negociadas em futuros. A segunda centraliza a análise nos fatores endógenos à indústria de futuros, especialmente o desenho do

\footnotetext{
${ }^{8}$ A BM\&F surgiu em 9 de maio de 1991 , da fusão entre a Bolsa Mercantil \& de Futuros e a Bolsa de Mercadorias de Săo Paulo.
} 
contrato, pois se as especificações contratuais não atraírem nem especuladores nem hedgers irá fracassar.

$\mathrm{Na}$ literatura recente há autores que desenvolveram modelos teóricos capazes de antecipar se determinado contrato irá fracassar ou não. É o caso do trabalho de Black (1986) que associa os fatores de sucesso dos contratos tanto às características da commodity quanto às do desenho do contrato, Telser \& Higinbotham (1977) analisam os custos e beneficios de se transacionar em mercados futuros organizados.

Há o trabalho de Pennings \& Leuthold (1999) que consideram a análise do sucesso ou fracasso de um contrato futuro como sendo multidisciplinar, que implica em considerar os aspectos contratuais e inerentes à commodity, como suas características e a forma como os agentes são incentivados a utilizar o mecanismo de mercados futuros.

\subsection{Abordagem característica da commodity}

\subsubsection{Estocagem}

A commodity deve ser estocável a fim de que o mercado futuro cumpra uma de suas funções: a alocação temporal de estoques, a qual permite aos possuidores de grandes estoques a escolha pela venda no presente ou no futuro. O papel do mercado é, então, o de prover um hedge contra os riscos das variações de preço ao se carregar estoques.

\subsubsection{Homogeneidade}

Os contratos no mercado futuro são regidos por regras claras acerca de todas as especificações que envolvem a commodity; como tamanho, cor, peso. Portanto, a homogeneidade daquela é necessária a fim de que possa satisfazer a um padrão particular preestabelecido e ser transacionada em mercados futuros. Segundo Black $(1986$, p. 8) a importância desta padronização é para que a negociação seja efetuada sem inspeção visual ou oral, assim cada comprador e vendedor saberá com certeza o que está recebendo ou entregando. 
A questão da homogeneidade está, de acordo com Lazzarini (1997, p. 94), intimamente relacionada à especificidade do ativo ${ }^{9}$, que se refere ao grau de dificuldade em se dar usos ou usuários alternativos para determinado ativo. Portanto, quanto maior a especificidade do ativo maior a dificuldade de compartilhá-lo, dificultando a implantação de um contrato futuro, dado que para a viabilização deste exige-se uma padronização dos atributos da commodity.

Para Teixeira (1992, p. 22) "um contrato de padronização dificil, cujos lotes entregues devem ser sempre previamente inspecionados e cuja avaliação do atendimento de pré-requisitos envolve critérios subjetivos, dificilmente terá sucesso, em função dos custos, tempo e disputa que certamente envolverão sua liquidação”. A especificidade mantém, assim, uma relação inversa com o sucesso dos contratos.

O algodão é classificado segundo o tipo e o comprimento comercial. A classificação é do melhor ao pior tipo: $3,3 / 4,4,4 / 5,5,5 / 6,6,6 / 7,7,7 / 8,8$ e 9 , seguidos dos tipos defeituosos ou abaixo do padrão. Já a classificação por comprimento é feita em milímetros: 27/28, 28/30, 29/30, 30/32 e 32/34. (Michellon, 1999, p. 94). No caso do algodão objeto de negociação do contrato futuro da BM\&F é o tipo 6 para melhor com comprimento de fibra de 30 a 32 milímetros.

\subsubsection{Volatilidade do preço}

É essencial para os mercados futuros a existência de oscilações nos preços, pois é esta que possibilita aos hedgers e especuladores a utilização do mercado. Os primeiros o fazem para se defender das variações nos preços e os últimos para lucrar com tais movimentos.

Quanto mais volátil for o preço de um dado bem, maior será a incerteza quanto a seu preço no futuro. Se determinada mercadoria, independentemente de ação governamental, não oferece condições para variações de preços, não haverá estímulo para sua negociação. O contrato futuro obterá sucesso se não houver controle governamental sobre preços, produção e comercialização do produto no mercado físico.

\footnotetext{
${ }^{9}$ Este conceito foi desenvolvido por Williamson (1985, p. 95)
} 
'Mercados futuros são aqueles em que se negocia a incerteza com relação aos preços futuros. Se essa incerteza é eliminada ou reduzida pela ação do governo ou se essa ação modifica constantemente as características do mercado, não há condições para o sucesso de um contrato futuro" (Teixeira, 1992, p. 22).

O algodão sempre recebeu a influência das políticas governamentais que contribuíram para a baixa volatilidade do preço ao longo de sua história, através, principalmente, de políticas de preço mínimo.

Segundo Telser (1981) apud Black (1986, p. 8) se a variabilidade do preço de uma commodity cai, irá resultar na queda da demanda por negócios futuros devido a menor necessidade de hedging. O baixo volume de contratos negociados reduz a liquidez, conduzindo a um incremento dos custos de comercialização, interpretado como margens e comissões. $O$ alto custo unitário reduz a demanda por negócios, e conseqüentemente, o volume.

Hull (1995, p. 270) define volatilidade como sendo "a nossa incerteza quanto aos retornos proporcionados pela ação". Para se obter a volatilidade diária anualizada o autor propõe o seguinte procedimento:

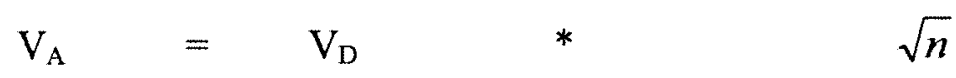

$($ Volatilidade ano $)=($ Volatilidade dia $) * \quad\left(\right.$ raiz do $n^{\circ}$ de dias de negociação por ano $)$

onde:

$$
\mathrm{V}_{\mathrm{D}}=\sqrt{\frac{1}{n-1} \sum_{i=1}^{n}\left(u_{i}-\bar{u}\right)^{2}} ; \quad \mathrm{u}_{\mathrm{i}}=\ln \left(\frac{S_{i}}{S_{i-1}}\right)
$$

$S_{\mathrm{i}}$ é o preço da commodity no final do i-ésimo intervalo $(i=0,1, \ldots, \mathrm{n})$ $\mathrm{n}+1$ observações e $\bar{u}$ é a média de $u_{\mathrm{i}}$ 
Para Teweles \& Jones (1987, p. 589) o preço do algodão é determinado por mudanças na oferta e demanda e por políticas governamentais. As variações na demanda são importantes e seu impacto significativo, mas ocorrem lentamente. Por outro lado a oferta pode afetar os preços significativamente e de forma rápida (estoques, chuvas, temperaturas extremas). As políticas governamentais, como visto no decorrer da Introdução desta dissertação, têm tido uma influência histórica sobre os preços do algodão, através de subsídio às exportações e outras políticas de incentivo.

No caso brasileiro, nos anos recentes, a oferta de algodão tem sido crescente dado o aumento de produtividade da cultura, além da expansão da área plantada, como notado na Tabela 2. Quanto à comercialização, esta tem sofrido influência das intervenções governamentais através do PEP e do Programa de Opções de Venda, os quais garantem o preço mínimo para os produtores - tornando-se um balizador dos preços no físico que irão variar em função daqueles leilões. Assim, o Governo assume o risco de oscilação dos preços. O algodão, como pode ser notado na Tabela 4, apresenta a menor volatilidade dos produtos agropecuários negociados na BM\&F. Pode-se inferir que o Governo ao atuar através dos Programas de Preço Mínimo acaba anulando o risco de oscilação dos preços e atuando de forma negativa para o sucesso do contrato futuro de algodão da BM\&F.

Tabela 4. Volatilidade do preço à vista de commodities selecionadas (maio de 1998 a janeiro de 2000)

\begin{tabular}{l|llllll}
\hline & Álcool Anidro & Açúcar & Algodão & Boi & Café & Soja \\
\hline Volatilidade & $12,13 \%$ & $13,63 \%$ & $5,17 \%$ & $7,27 \%$ & $23,87 \%$ & $5,43 \%$ \\
\hline
\end{tabular}

\subsubsection{Amplo mercado físico}

A importância deste item está, em primeiro lugar, no impedimento ou na dificuldade existente para um agente estabelecer o domínio do mercado caso a oferta da commodity seja grande e, em segundo lugar, um mercado amplo atrairá um número 
significativo de hedgers, e um largo mercado à vista irá tender a prover um contínuo e disciplinado encontro das forças de demanda e oferta.

\subsubsection{Oferta irrestrita}

Refere-se à habilidade do bem se mover livremente no mercado. Para tanto dois aspectos devem ser evitados. O primeiro são as forças anticompetitivas. Dificilmente um mercado obterá sucesso se for controlado ou pelo governo, ou por um cartel, ou por um monopólio. Segundo Black (1986, p. 9) o controle da oferta pode ditar os preços e levar à manipulação. Hieronymus $(1977$, p. 20$)$ ressalta que no mercado onde a demanda e a oferta são livres os preços estão em constante mudança. É a existência destas constantes flutuações nos preços que conduzem ao sucesso dos mercados futuros.

A "cotonicultura empresarial", como visto na seção 2.3, é caracterizada por grandes propriedades e intensiva em capital. Tal modelo apresenta altos custos de produção se comparado com as demais atividades como a soja, exigindo elevados montantes de capital para entrar e se manter no negócio, assim se caracterizando como uma estrutura integrada.

A estrutura integrada tem se tornado uma característica do SAG-A, principalmente após a abertura comercial que eliminou os agentes pequenos $\mathrm{e}$ ineficientes. $\mathrm{Na}$ indústria, a integração ocorre da fiação à tecelagem. Portanto, têm sido eliminadas transações de mercado intranível agrícola e intranivel industrial.

A intervenção governamental também deve ser evitada, como exemplo, Telser \& Higinbotham (1977) citam o caso do algodão nos Estados Unidos, no qual o mercado reacendeu após a saída do governo.

\subsubsection{Efeitos do ambiente macroinstitucional}

Para evidenciar a importância deste atributo Lazzarini (1997, p. 97) cita o caso das políticas governamentais que incidem sobre o ativo, como a política de preços mínimos - ao reduzir as incertezas quanto aos preços futuros atua como um mecanismo de hedging. Ressalta, ainda, a questão da incidência de regulamentação governamental 
sobre os negócios futuros destacando as imposições que são colocadas às bolsas quando do lançamento de um novo contrato e que podem influenciar negativamente o sucesso dos contratos.

\subsection{Abordagem desenho do contrato}

O sucesso das transações não pode ser atribuído somente às características da commodity, devem ser levadas em consideração as especificações do contrato, e a forma como contemplam aos hedgers e especuladores.

Somente a presença de hedgers não é garantia do sucesso de um contrato. A presença dos especuladores também é importante para a efetividade dos mercados futuros. Sua relevância está em lidar e fazer vários investimentos e, constantemente interpretar informações. Assim enquanto negociam são capazes de julgar se determinado mercado não está em desordem e se seus preços estão ou muito altos ou muito baixos (Leuthold et al, 1989, p. 5). A especulação é uma variável essencial na formação de qualquer preço de mercado.

Para um contrato ter sucesso são necessárias além das características atribuídas ao produto, que o contrato atenda a algumas exigências como a atratividade para hedgers e especuladores, e inexistência de manipulação. Finalmente há de se considerar a questão da padronização dos contratos, que implica numa aderência menor dos mesmos às especificidades do ativo, ou seja, resulta na redução da capacidade de hedging dos contratos (Lazzarini, 1997, p. 99). Assim, há a escolha pela redução dos custos de negociação em mercados organizados de um substituto próximo ou pelo aumento de eficiência proporcionado por um hedging perfeito, mas sem liquidez.

Será visto na seção seguinte que as bolsas consideram um balanço entre o aumento do custo de liquidez de um novo contrato e a redução do risco residual provida aos hedgers pelo novo mercado. O novo contrato terá sucesso somente se oferecer ao hedger suficiente beneficio na redução do risco capaz de compensar o custo de liquidez mais alto por seu uso. O hedging ideal é aquele no qual a commodity especificada para entrega no contrato futuro "casa" exatamente com a mantida à vista. Assim, os 
movimentos de preço no mercado à vista e futuro serão praticamente paralelos (quase predizíveis) e o hedging poderá remover quase todo o risco da mudança de preço. Para os possuidores de uma variedade de commodity no mercado à vista inexistente no futuro, $o$ hedge ideal não existe, sendo o cross hedge a única possibilidade.

$O$ cross hedging ocorre quando $o$ hedger usa $o$ mercado futuro de uma commodity diferente da sua posição à vista. A estratégia é efetiva na redução do risco quando há uma relação de dependência entre o ativo a ser hedgeado e o contrato futuro de outra commodity.

O novo contrato geralmente é menos líquido que o já estabelecido no mercado futuro. Os custos de transação por negócio num novo mercado são maiores que os transacionados nos já existentes. Os hedgers são consumidores de serviços de liquidez, sendo esta despesa considerada numa análise custo-beneficio de qual mercado usar como veículo de hedging. (Leuthold et al, 1989, p. 146).

Os hedgers irão racionalmente escolher menor proteção de risco devido à redução do custo de liquidez. Se o risco da mudança de preço da commodity pode ser suficientemente reduzido pelo cross hedging num contrato líquido existente, então os hedgers terão pouco incentivo para usar o novo contrato futuro (Black, 1986).

Ressalta-se, ainda, que vários estudos empíricos já foram desenvolvidos para mostrar a evidência de que novos contratos introduzidos falham se existir um mercado substituto próximo. Como exemplo Silber (1981) retrata a importância das especificações dos contratos como variável de análise para as bolsas. Em alguns casos o lançamento de novos contratos irá fracassar se houver substituto próximo dado a liquidez do já existente, o que faz as bolsas tomarem a decisão de revisão de seus contratos e então relançarem-no com modificações.

Para tanto Black (1986) desenvolve uma abordagem na qual busca relacionar o sucesso ou fracasso dos contratos negociados à existência de commodities substitutas. A palavra eficiente é usada no sentido de custo de liquidez baixo e risco residual baixo. Se o contrato substituto existente apresentar um risco residual elevado cria-se a oportunidade para a introdução do novo contrato. Se não, a redução de risco proporcionada pelo novo 
não irá compensar a falta de liquidez do mesmo, e os hedgers continuarão a preferir o cross-hedge.

À medida que se eleva a especificidade do desenho contratual está se restringindo o contrato a um número menor de participantes, resultando num aumento dos custos de transação, devido à redução de liquidez e ao aumento da possibilidade de manipulação. $\mathrm{O}$ aumento da efetividade de hedging traz consigo hedgers com elevado grau de aversão ao risco. No entanto há hedgers que preferem uma efetividade de hedging menor se thes for oferecido menores custos de transação proporcionados por negociação em bolsas com maior volume de negociação (Lazzarini, 1997).

No caso de se relaxar a especificidade e desenhar um contrato que atenda a vários padrões de qualidade, locais de entrega, etc, a efetividade do hedging reduz-se, mas haverá um aumento no número de potenciais participantes possibilitando reduções nos custos de transação ex-ante.

A análise do trade-off pode ser estendida aos contratos futuros, buscando verificar se um contrato que garanta maior efetividade de hedging poderá ter mais sucesso que outro com maior volume negociado (e com menores custos de transação), embora com menor efetividade. Como exemplo Lazzarini (1997) cita a competição entre bolsas com alta liquidez e as bolsas locais que buscam ganhar mercados. Neste exemplo, os indivíduos estariam optando por efetividade de hedging proporcionada pelas bolsas locais ao invés dos menores custos de transação possibilitados pelas bolsas de maior liquidez.

\subsection{Abordagem cross-hedge eficiente}

A abordagem cross-hedge eficiente proposta por Black (1986, p. 24) relaciona o sucesso ou o fracasso dos contratos futuros à existência de uma commodity substituta. Se um contrato futuro já existe para um substituto próximo, então a redução do risco residual derivado do hedge perfeito (se comparado ao cross hedge) é pequena e pode não contrabalançar o custo de se transacionar num mercado novo e de pouca liquidez. A 
chance de sucesso deste contrato é pequena, pois já existe um cross-hedge disponível servindo aos hedgers da commodity. Todavia, se o cross-hedge existente deixa o hedger com uma larga quantidade de risco residual, um nicho pode ser criado para o novo contrato. Ademais, se o mercado do cross-hedge não é pesadamente líquido, aumentamse as chances de sucesso do novo contrato.

\subsubsection{O modelo de Black}

A proposta de Black $(1986)^{10}$ é especificar um modelo capaz de explicar o sucesso dos contratos. O primeiro problema encontrado foi quanto à especificação da variável independente, já que sucesso contratual é uma variável qualitativa, portanto seria melhor se fosse encontrada uma variável quantitativa contínua. Assim, foi usado volume negociado como medida de sucesso, já que para as bolsas o sucesso está relacionado ao alto volume transacionado.

Todavia, ao invés de estabelecer um valor de corte pode-se examinar o sucesso relativo de todos os contratos baseado no volume negociado. Sucesso está atrelado a alto volume e fracasso a baixo. Esta medida contínua de sucesso afasta problemas de estimação que poderiam acompanhar a medida qualitativa, caso fosse usada como variável dependente.

Quanto às variáveis explicativas, isto é, os determinantes do sucesso, constitui-se nos critérios que a Bolsa implicitamente leva em consideração na escolha da commodity e nas especificações do desenho do contrato. A abordagem que agrega tais considerações é a do cross-hedge eficiente. $\mathrm{Na}$ verdade, centraliza-se a análise em dois aspectos: a habilidade de reduzir o risco da mudança de preço da commodity, e sua liquidez.

A equação (1) focaliza esta hipótese, na qual o volume negociado no contrato futuro $\mathrm{i}$ está relacionado ao risco residual relativo da commodity $\mathrm{i}$ do cross-hedging versus o own hedging $\left(R_{R}\right)$ e o custo de liquidez de se usar o mercado futuro próprio

\footnotetext{
${ }^{10}$ Para maiores detalhes sobre a metodologia deste modelo consultar Black, D (1986). Success and Failure of Futures Contracts: theory and empirical evidence.
} 
(own) ao invés do melhor mercado futuro cross líquido existente para a commodity i $(\mathrm{CLIQ})$

$$
\begin{gathered}
\text { VOLUMEi }=f\left(\mathrm{RR}_{\mathrm{i}}, \mathrm{CLIQ}_{\mathrm{i}}, \ldots\right) \\
\frac{\text { VOlume }_{i}}{\partial R R_{i}} \geq 0 \quad \frac{\partial \text { Volume }_{i}}{\partial \text { CLIQ }_{i}} \leq 0
\end{gathered}
$$

A primeira derivada é positiva, pois se a redução do risco da mudança de preço (alto risco residual do cross hedging) for alto então se pode predizer que a inovação contratual obterá sucesso. Já a segunda derivada é negativa indicando que quanto mais líquido o mercado futuro usado para cross-hedge menor a chance de sucesso do novo contrato.

Devem ser agregados à equação (1), a fim de torná-la completa, outros fatores que possam influenciar o sucesso ou fracasso de um contrato, como a volatilidade do preço à vista da commodity (PVARi) e a existência de um amplo mercado à vista para a commodity (SIZEi). Assim, tem-se a equação (2)

$$
\begin{gathered}
\text { VOLUMEi }=f(\text { RRi, CLIQi, PVARi, SIZEi) } \\
\frac{\partial \text { Volume }_{i}}{\partial P \text { var }_{i}} \geq 0 \\
\frac{\partial \text { Volume }_{i}}{\partial \text { Size }_{i}} \geq 0
\end{gathered}
$$

Os sinais das derivadas parciais anteriores indicam uma relação positiva destas variáveis com o sucesso. No primeiro caso quanto maior a volatilidade nos preços, maior a necessidade de hedging. No segundo, quanto maior o tamanho do mercado a vista maior a possibilidade de existência de potenciais participantes. 
Espera-se que quantidades crescentes de necessidade de hedging e especulação exerçam influência positiva sobre sucesso. Além disso, espera-se também que todas as variáveis interajam na influência sobre o volume; isto é, a derivada parcial de cada variável depende do nível das outras variáveis. Por exemplo, não irá importar o nível de liquidez do cross-hedge se a volatilidade preço do mercado a vista for extremamente baixa.

A forma funcional possivel é a seguinte

Volume $_{i}=\beta_{0}{ }^{*} R_{i}^{\beta_{1} *}{ }^{*} \operatorname{CLIQ}_{i}^{\beta_{2} *}{ }^{2} \operatorname{PVAR}_{i}^{\beta_{3} *} \operatorname{SIZE}_{i}^{\beta_{4} *} e_{i}^{u_{i}}$

Que pode ser transformada na seguinte especificação log-log

$$
\ln \text { Volume }_{i}=\ln \beta_{0}+\beta_{1} \ln R R_{i}+\beta_{2} C L I Q_{i}+\beta_{3} \ln P V A R_{i}+\beta_{4} \ln S I Z E_{i}+u_{i}
$$

Com as seguintes derivadas parciais: $\beta_{1}>0 ; \beta_{2}<0 ; \beta_{3}>0 ; \beta_{4}>0$.

A relevância deste capítulo foi para mostrar que os determinantes para o sucesso ou fracasso de um contrato futuro estão atrelados à análise dos fatores que envolvem as características do produto, e às que envolvem as características do contrato e de competição com contratos já existentes e líquidos.

$\mathrm{Da}$ análise dos capítulos 2 e 3 pode-se depreender alguns fatores que poderiam estar induzindo ao não funcionamento do contrato futuro de algodão da BM\&F, dentre os quais pode-se citar a existência de um hedge natural pelas fiações, a integração tanto na parte agrícola do SAG quanto na parte industrial, e a intervenção governamental através dos programas de preço mínimo. 


\section{EFICIÊNCIA EM MERCADOS FUTUROS}

\subsection{Discussão Teórica}

Os capitulos iniciais foram importantes para identificar quem seriam os agentes a utilizar o mercado futuro de algodão, no caso, produtores e indústrias de fiação. Os traders são também importantes, mas estão atrelados a mercados de exportação, como açúcar, café e soja. Este capítulo tem por objetivo discutir o conceito de eficiência em mercados futuros a fim de verificar se durante o tempo em que o contrato de algodão em pluma da BM\&F foi negociado, o mesmo era ou não um instrumento efetivo de seguro de preços.

Para tal o capítulo foi dividido em três partes. Na primeira é discutido o conceito teórico de eficiência de mercado. $\mathrm{Na}$ segunda verificam-se alguns procedimentos que devem ser considerados quando da análise dos dados, através da utilização de conceitos econométricos. E na terceira é feita a ligação entre as partes anteriores, na qual o leitor sedimentará a necessidade de adoção daqueles procedimentos econométricos para dar continuidade à metodologia de cálculo da eficiência de mercado.

Uma das funções dos mercados futuros é a de possibilitar aos hedgers de um determinado produto uma proteção contra futuras variações adversas de preços. Através do hedge "é possivel transferir o risco de perdas inesperadas de capital para outro agente disposto a carregá-lo, o qual pode ou não estar envolvido diretamente no processo de produção e de comercialização da mercadoria" (Arbex, 1999, p. 98).

Também se atribui aos mercados futuros a função de sinalização de preços. Se determinado mercado futuro for eficiente então suas cotações refletirão as informações disponiveis de oferta e demanda e as opiniões dos agentes; sendo assim um bom previsor dos preços que irão vigorar no mercado a vista na data do vencimento do contrato. 
A relevância do mercado ser um sinalizador dos preços que irão vigorar no mercado a vista está na precisão do processo de alocação intertemporal dos recursos entre os ativos, possibilitando aos agentes uma tomada de decisão alocacional eficiente. Deve-se ressaltar que "o conteúdo informacional embutido nas cotações de dado mercado futuro tem importante impacto alocacional para a economia como um todo" (Arbex, 1999, p. 102).

Tanto hedgers quanto especuladores buscam algum tipo de proteção no mercado futuro. Os hedgers se protegem de variações adversas nos preços de seu produto. No caso de uma fiação, por exemplo, busca se proteger de uma alta no preço de seu insumo - o algodão em pluma. Já o especulador, tomador de risco, busca proteger seu lucro e/ou rentabilidade também contra uma variação adversa dos preços no futuro.

Parte-se do pressuposto de que tais agentes sejam racionais (hedgers e especuladores), que tomem suas decisões baseadas no conjunto das informações disponíveis e sejam neutros ao risco. Então, determinado mercado futuro será eficiente se contiver toda aquela informação, e se a expectativa futura do preço a vista da commodity na data de vencimento do contrato for igual ao preço futuro corrente, ou seja:

$E_{t-1} S_{t}=F_{t-1}$

Onde:

$E_{t-1} S_{t}:$ é a expectativa futura do preço a vista em t-1

$F_{t-1}$ : é o preço futuro em $\mathrm{t}-1$, para o vencimento do contrato em $\mathrm{t}$

Assumindo expectativas racionais, então:

$S_{t}=E_{t-1}\left(S_{t} / \Omega_{t-1}\right)+u_{t}$

Onde:

$\left(\Omega_{t-1}\right)$ : denota o conjunto de informações disponíveis no período t-1 
$u_{t}:$ é a expectativa racional do erro

Pode-se reescrever (5) da seguinte forma:

$S_{t}=\alpha+\delta F_{t-1}+u_{t}$

Para se verificar a hipótese conjunta de eficiência de mercado e estimativas não viesadas, testam-se as seguintes restrições:

$\alpha=0, \delta=1$

Se o preço futuro, $F_{t-1}$, contiver todas as informações relevantes para prever o preço a vista do período seguinte $S_{t}$, como a definição de eficiência de mercado implica, então $F_{t-1}$ pode ser um previsor não-viesado do futuro preço a vista. (Crowder \& Hamed, 1993, p. 933)

Mckenzie \& Holt (1998, p. 2) ressaltam que a rejeição das hipóteses listadas em (7.1) implicará nos seguintes resultados:

a) Mercado ineficiente.

b) Um prêmio de risco constante poderá existir, o que torna as previsões de mercado viesadas, mas possivelmente eficientes.

c) É possível que a variação temporal do risco de prêmio seja inerente ao mercado, prevenindo os preços futuros isoladamente de gerar previsões não viesadas do preço a vista futuro.

Arbex (1999, p. 103) ressalta ainda que "a acumulação da informação com a passagem do tempo... o valor do $\mathrm{R}^{2}$ possa aumentar monotonicamente com $\mathrm{t}-\mathrm{i}$. Assim, os preços dos contratos futuros mais próximos devem estimar melhor o preço físico no vencimento do que os preços dos contratos futuros mais distantes". 
Crowder \& Hamed (1993, p. 934) discutiram a questão da violação das restrições de (7.1), cuja explicação encontrada na literatura refere-se à existência de um prêmio de risco, variante no tempo. Este prêmio pode ser considerado uma explicação satisfatória da existência de retornos especulativos diferentes de zero em mercados futuros. Os autores ainda ressaltam que a existência destes retornos não implica na ineficiência dos mercados, mas apenas que os investidores estariam exigindo uma compensação pelo risco que assumem.

\subsection{Procedimentos Econométricos}

Mckenzie \& Holt (1998, p. 2) argumentam que a literatura baseia-se na estacionariedade dos dados para realizar testes apropriados sobre eficiência de mercado e estimadores não viesados.

Uma série é dita estacionária se a média e a variância são constantes ao longo do tempo, e se o valor da covariância entre dois períodos de tempo depende somente da distância entre aqueles períodos de tempo, e não do valor atual (corrente) em que a covariância é computada.

Média: $\quad E\left(Y_{t}\right)=\mu$

Variância: $\operatorname{var}\left(Y_{t}\right)=E\left(y_{t}-\mu\right)^{2}=\sigma^{2}$

Covariância: $\gamma_{\mathrm{k}}=E\left[\left(\mathrm{Y}_{\mathrm{t}}-\mu\right)\left(\mathrm{Y}_{\mathrm{t}+\mathrm{k}}-\mu\right)\right]$

A importância da estacionariedade das séries é a de permitir o uso da média, variância e das autocorrelações da amostra para estimar os atuais parâmetros dos dados geradores do processo (Enders, 1995, p. 86).

Assim se as séries de preços forem não estacionárias os testes de hipóteses baseados na equação (7) fornecerão resultados viesados. "A regressão de uma variável não-estacionária, que só se tornará estacionária pela diferença numa tendência determinística, geralmente conduz a problemas de regressão espúria, envolvendo inferências inválidas baseados nos testes t e F" (Mckenzie \& Holt, 1998, p.2). 
A regressão espúria ${ }^{11}$ é uma possibilidade comum nas regressões que envolvem dados em séries temporais. O problema surge por que as duas séries exibem ou são caracterizadas por uma tendência (sustentada por movimentos de alta ou baixa). Assim o coeficiente de determinação da regressão, $O \mathrm{R}^{2}$ observado, é devido à presença da tendência, e não em função da existência de uma relação entre as duas variáveis.

Tal como Mckenzie \& Holt (1998), Gujarati (1995, p. 725), recomenda utilizar a primeira diferença das variáveis a fim de torná-las estacionárias.

Um dos testes utilizados para se verificar a estacionariedade da série é o de raiz unitária (Dickey \& Fuller, 1979). Considere o seguinte modelo:

$Y_{t}=Y_{t-1}+u_{t}$

onde $u_{t}$ é o termo de erro estocástico que segue as hipóteses clássicas de média zero, variância constante $\sigma^{2}$, e não autocorrelação.

A equação (11) é um processo autoregressivo de primeira ordem - AR (1) ${ }^{12}$. Se o coeficiente de $\mathrm{Y}_{\mathrm{t}-1}$ é de fato igual a 1, tem-se um problema de raiz unitária, ou seja, uma situação de não-estacionariedade.

Considere a seguinte regressão:

$Y_{t}=\rho Y_{t-1}+u_{t}$

se de fato $\rho=1$, então diz-se que a variável estocástica $Y_{t}$ tem uma raiz unitária.

Pode-se expressar a equação (12) da seguinte forma:

$$
\Delta Y_{t}=(\rho-1) Y_{t-1}+u_{t}
$$

\footnotetext{
${ }^{11}$ O termo espúrio, segundo Gujarati $(1995$, p. 709, 724 e 725) refere-se a regressão de uma variável em outra, cujo $\mathrm{R}^{2}$ desta regressão será elevado, mas sem representatividade ou significado.

${ }^{12}$ Processo autoregressivo é uma regressão na qual se regride o valor de $\mathrm{Y}$ em $\mathrm{t}$, em relação a seu valor em $(\mathrm{t}-1)$.
} 


$$
=\delta Y_{t-1}+u_{t}
$$

onde $\delta=(\rho-1)$ e $\Delta$ é o operador da primeira diferença.

Se $\delta$ for de fato zero, pode-se reescrever (13.1)

$$
\Delta Y_{t}=\left(Y_{t}-Y_{t-1}\right)=u_{t}
$$

Em econometria uma série que contém uma raiz unitária é um passeio aleatório. A equação anterior mostra que a primeira diferença de um passeio aleatório $\left(=u_{t}\right)$ é uma série estacionária pois por hipótese $\mathrm{u}_{\mathrm{t}} \mathrm{e}$ puramente randômica.

Assim se uma série tem de ser diferenciada uma vez para se tornar estacionária diz-se que a série original é integrada de ordem 1 , cuja notação é $\mathrm{I}(1)$. Se forem necessárias duas diferenciações então será integrada de ordem 2. A diferenciação das séries é um dos métodos mais utilizados para obter a estacionariedade dos dados.

No entanto Hamilton (1994) faz uma ressalva quanto à regressão das variáveis diferenciadas. De acordo com o autor se a regressão for feita na forma diferenciada podese estar perdendo uma valiosa relação de longo prazo entre as variáveis dadas ou expressa com as mesmas em nivel. A maioria das teorias e/ou relações econômicas estão expressas com as variáveis em nivel e não na primeira diferença. $\mathrm{O}$ autor usa como exemplo o postulado de Milton Friedman no qual o nível de consumo é função do nível de renda, e não da primeira diferença do nível de renda.

A relação de longo prazo a que se refere Gujarati (1995) é o conceito intuitivo de cointegração. Segundo Arbex (1999) duas variáveis não-estacionárias poderão caminhar juntas e com movimentos paralelos, e apresentar no longo prazo uma relação de equilíbrio. Mesmo que $S_{t}$ e $F_{t-1}$ sejam não estacionários, por terem os mesmos movimentos não poderão distanciar-se, pois sua diferença é estacionária. 
O conceito de cointegração foi introduzido por Engle \& Granger (1987). Para explicitar tal conceito considere um conjunto de variáveis econômicas num equilíbrio de longo-prazo:

$\beta_{1} x_{1 t}+\beta_{2} x_{2 t}+\ldots+\beta_{n} x_{n t}=0$

Se $\beta$ e $x_{t}$ denotarem os vetores $\left(\beta_{1}, \beta_{2}, \ldots, \beta_{n}\right)$ e $\left(x_{1 t}, x_{2 t}, \ldots, x_{n t}\right)^{\prime}$, o sistema está em equilíbrio de longo-prazo quando $\beta x_{t}=0$. $O$ desvio da relação de equilíbrio de longo prazo - o chamado erro de equilíbrio - $e_{h}$ é tal que

$e_{t}=\beta x_{t}$

Se o equilibrio for significativo pode ser o caso de um erro de equilibrio cujo processo é estacionário. Engle \& Granger (1987) estabeleceram então a seguinte definição para cointegração.

"Os componentes de um vetor $\mathrm{x}_{\mathrm{t}}=\left(\mathrm{x}_{1 \mathrm{t}}, \mathrm{x}_{2 \mathrm{t}}, \ldots, \mathrm{x}_{\mathrm{nt}}\right)$, são ditos cointegrados de ordem $d, b$, e denotados por $x_{t} \sim C I(d, b)$ se

1 - todos os componentes de $x_{t}$ são integrados de ordem $d$

2 - Se existir um vetor $\beta=\left(\beta_{1}, \beta_{2}, \ldots, \beta_{n}\right)$ cuja combinação linear $\beta x_{t}=\left(\beta_{1} x_{1 t}+\beta_{2} x_{2 t}+\right.$ $\left.\ldots, \beta_{n} x_{n t}\right)$ é integrada de ordem $(d-b)$, onde $b>0$. O vetor $\beta$ é chamado de vetor cointegrante.

Assim, se os preços futuros e a vista são não estacionários e requerem a diferenciação para torná-los estacionários, então a maioria das combinações entre aquelas séries será não estacionária. No entanto, pode existir um vetor de cointegração que torne a combinação linear específica das duas séries estacionária. 
Mckenzie \& Holt (1998) então afirmaram que se a expressão abaixo é uma série estacionária, $\alpha$ e $\delta$ são os termos cointegrantes e a regressão: $S_{t}=\alpha+\delta F_{t-1}+u_{t}$ é cointegrada ou de equilíbrio.

$u_{t}=S_{t}-\alpha-\delta F_{t-1}$

Arbex \& Rotatori (2000, p. 13) citando Hakkio \& Rush (1989) ressaltam a importância de $S_{t}$ e $F_{t-1}$ serem cointegrados e o termo de erro $\left(u_{t}\right)$ estacionário. "Se essas variáveis são cointegradas com um vetor de cointegração igual a 1 , então essas séries não podem se distanciar porque a diferença $S_{t}-F_{t-1}$ é estacionária, e igual a $u_{t}$ ".

\subsection{Justificativa para a Utilização dos Procedimentos Econométricos no Cálculo da} Eficiência de Mercado

Com relação à cointegração entre as séries de preço a vista e futura, Lien (1996, p. 779) conclui, em seu trabalho, que a não consideração desta relação de longo prazo entre as séries, expressa pela cointegração pode conduzir à determinação de uma posição hedgeada em futuros menor que a razão de hedge ${ }^{13}$ ótima, implicando numa performance de hedge não ótima (ou pobre).

A cointegração entre duas séries é condição necessária, mas não suficiente para eficiência de mercado. O preço a vista e futuro são determinados pelos mesmos fundamentos e então eficiência irá implicar no não distanciamento entre eles.

Entretanto, a cointegração não afasta as ineficiências de mercado de curto-prazo, nos quais as informações passadas podem implementar ou incrementar as previsões futuras do preço a vista. Assim, segundo Arbex (1999, p. 104) a eficiência requer o parâmetro $\delta$ igual a 1 . Há ainda uma ressalva apresentada por Arbex \& Rotatori (2000, p.

\footnotetext{
${ }^{13}$ A razão de hedge refere-se ao número de contratos futuros que devem ser mantidos a fim de hedgear uma determinada quantidade no fisico.
} 
14) que num mercado eficiente pressupõe-se o termo de erro como sendo um ruído branco $^{14}$, e a cointegração exige apenas a sua estacionariedade.

O objetivo da dissertação, como ressaltado na Introdução, é o de verificar as relações entre o mercado a vista brasileiro de algodão e as possibilidades de hedge que podem ser realizadas nas bolsas BM\&F e NYBOT. Para tanto, primeiro será feito o procedimento de cálculo da eficiência de hedge, utilizando a análise de cointegração, em cada uma destas bolsas.

Espera-se que não exista uma relação de longo prazo entre o mercado a vista de algodão e os preços futuros da NYBOT, pois a formação do preço do algodão é doméstica (não sendo influenciada por aspectos referentes a oferta e demanda mundial). Como o Brasil não tem representatividade no quadro de oferta e demanda mundial, acredita-se que as cotações da NYBOT não irão refletir, portanto, as variações no mercado fisico brasileiro. Além das diferenças existentes nos períodos de safra e entressafra específicos para cada país.

\footnotetext{
${ }^{14}$ Segundo Enders $(1995$, p. 65$)$ um termo de erro $u_{t}$ será um ruído branco se cada valor na série tiver uma média zero, variância constante, e não apresentar correlação serial.
} 


\section{RESULTADOS E DISCUSSÕES ${ }^{15}$}

\subsection{Introdução}

Neste capítulo será verificada qual a opção de hedge é mais eficiente para o hedger nacional, se a da BM\&F ou a da NYBOT. Para tanto a análise será feita a partir da utilização do procedimento de cointegração. No entanto, o conceito sobre eficiência em mercados futuros, como notado no capítulo 4, pressupõe condições necessárias e suficientes para a escolha de qual opção é a mais eficiente.

A hipótese conjunta de eficiência de mercado e estimativas não viesadas pressupõe a verificação das seguintes restrições:

$\alpha=0, \delta=1$

A discussão sobre eficiência de mercado será dividida em duas partes. Na primeira será utilizado o procedimento de Engle \& Granger (1987) para verificar se as duas séries (preços a vista e futuro) cointegram, e obter, portanto, uma primeira resposta quanto à relação de longo prazo entre as variáveis.

Tal constatação é importante no sentido de que se tem por hipótese a não existência de uma relação de longo prazo entre o preço a vista do algodão em pluma no Brasil e o preço futuro do contrato de algodão negociado na NYBOT.

No entanto a existência de uma relação de longo prazo entre as variáveis não implica num contrato futuro eficiente para aquele preço a vista. Para tanto faz-se necessário testar o parâmetro $\delta$ igual a 1. Para tal verificação será utilizado o procedimento de Johansen (1988) que permite a inclusão de restrições na matriz a fim de testar as restrições especificadas em (7.1).

\footnotetext{
${ }^{15}$ Foi utilizado o pacote estatístico Econometric Views - Eviews 3.1 como programa para a resolução dos testes propostos na metodologia da dissertação.
} 


\subsection{Procedimento de Engle \& Granger}

A fim de se testar a eficiência dos contratos futuros de algodão das bolsas BM\&F e NYBOT foram utilizados para representar o preço vigente no mercado a vista brasileiro o Indicador de Preços do Algodão em Pluma ESALQ/BM\&F. No caso dos preços futuros foram utilizados os dados de $1^{\circ}$ vencimento para BM\&F e NYBOT ${ }^{16}$. Todos os dados foram convertidos para logaritmos naturais e expressos em centavos de dólar por libra-peso. A análise dos dados foi de 2/1/1997 a 1/7/2000 ${ }^{17}$. A utilização do primeiro vencimento deve-se ao fato de ser considerado a melhor proxy dos preços a vista.

A análise gráfica das três séries em conjunto é interessante, no sentido de que permite verificar que ESALQ e BM\&F se comportam no tempo de forma muito próxima; já ESALQ e NYBOT apresentam a mesma movimentação no tempo, mas com alguns descolamentos de curto prazo.

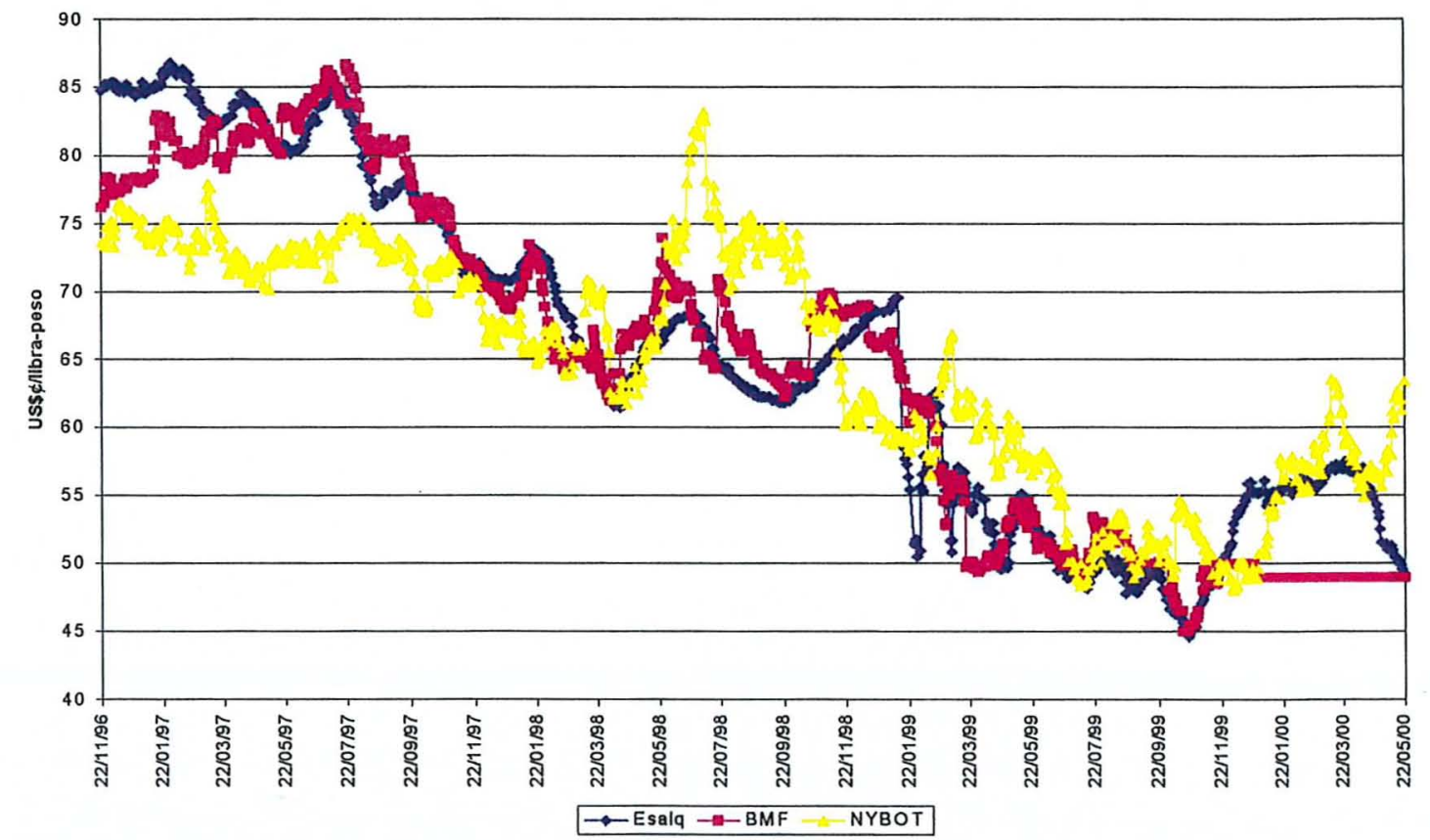

Figura 2 - Evolução do Indicador ESALQ/BM\&F e do $1^{\circ}$ vencimento do contrato futuro de algodão das bolsas BM\&F e NYBOT (1996 a 2000)

\footnotetext{
${ }^{16}$ Os contratos de algodão das bolsas BM\&F e NYBOT têm os seguintes vencimentos: março, maio, julho, setembro e dezembro. A série de primeiro vencimento refere-se ao vencimento mais próximo em aberto. A transição de um vencimento para o outro é realizada quando do início do aviso de entrega.

${ }^{17}$ Depois desta data não houve mais negócios no contrato futuro de algodão da BM\&F.
} 
A observação isolada do gráfico poderia conduzir a resultados equivocados quanto à verdadeira relação entre aquelas variáveis.

Verificou-se no capítulo 4 que o procedimento a ser utilizado para se testar a hipótese de eficiência dos mercados é o de cointegração, que segue a seguinte rotina:

As variáveis preço a vista $\left(\mathrm{S}_{\mathrm{t}}\right)$ e futuro $\left(\mathrm{F}_{\mathrm{t}-1}\right)$ são integradas de ordem 1: I(1), deseja-se determinar a existência de uma relação de equilibrio entre elas ${ }^{18}$ :

1. São realizados testes nas variáveis para verificar qual a ordem de integração das mesmas. Por definição, a cointegração pressupõe que as variáveis sejam integradas na mesma ordem. Então, deve-se primeiro testar cada variável a fim de determinar sua ordem de integração. Os testes Dickey-Fuller Aumentado -ADF (Dickey \& Fuller, 1979), Phillips-Perron (Phillips \& Perron, 1988) e KPSS (Kwiatkowski et al, 1992) podem ser utilizados para inferir o número de raizes unitárias, se houver, de cada uma das variáveis. Se as variáveis são integradas de diferente ordem, é possível concluir que elas não são cointegradas.

No presente trabalho a fim de verificar a existência de uma raiz unitária utilizou-se o teste de Dickey-Fuller Aumentado. O teste é implementado em etapas, partindo-se primeiro de um modelo completo como o especificado em (18), com constante $(\alpha)$, tendência $(\beta)$ e defasagens.

$$
\Delta y_{t}=\alpha+\beta_{t}+y_{t-1}+\sum_{i=1}^{k} \delta_{i} \Delta y_{t-i}+\varepsilon_{t}
$$

São tomados procedimentos de análise com o intuito de verificar a significância dos parâmetros $(\alpha$ e $\beta$ ). Se não forem significantes são implementadas as outras etapas do teste, considerando um modelo sem tendência. Se o parâmetro referente a tendência

\footnotetext{
${ }^{18}$ Baseado em Enders (1995, p. 355 a 421), Cointegration and error-correction models in Applied econometric time series.
} 
não for significante é implementado um outro teste considerando o modelo sem tendência e sem intercepto ${ }^{19}$.

Então, tomando a equação (18) deve-se testar a significância individual dos parâmetros. Tem-se a seguinte hipótese nula:

$\mathrm{H}_{0}:(\beta)=(0)$

$\mathrm{H}_{\mathbf{a}}: \beta \neq 0$

$\left|\tau_{\beta \tau}\right|<\left|\tau_{\beta \tau \tau}\right|^{20}$

Se $o \tau_{\beta}$ crítico for menor que $o \tau_{\beta T}$ rejeita-se a hipótese alternativa de significância do parâmetro $\beta$.

Para a constante, tem-se procedimento similar:

$$
\begin{aligned}
& \mathrm{H}_{0}:(\alpha)=(0) \\
& \mathrm{H}_{\mathrm{a}}: \alpha \neq 0 \\
& \left|\tau_{\alpha \tau}\right|<\left|\tau_{\alpha \tau \mathrm{T}}\right|
\end{aligned}
$$

Se $\circ \tau_{\alpha}$ crítico for menor que $\circ \tau_{\alpha \mathrm{TT}}$, rejeita-se a hipótese alternativa de significância do parâmetro $\alpha$. Os valores críticos tabelados para os testes de significância dos parâmetros $\alpha$ e $\beta$ estão na tabela 5 .

Depois de realizados os testes de significância individuais, parte-se para o teste de significância conjunto, a fim de corroborar os resultados anteriores. Assim,

$\mathrm{H}_{0}:(\alpha, \beta, \gamma)=(0,0,0)$

$\mathrm{H}_{\mathrm{a}}$ : pelo menos 1 diferente de zero

$\Phi_{2}<\Phi_{2 \mathrm{~T}}$

\footnotetext{
${ }^{19}$ Tal procedimento está relacionado a questðes de poder do teste.

${ }^{20} \mathrm{~T}$ tabelado.
} 
Se o $\Phi_{2}$ crítico for menor que o $\Phi_{2 \mathrm{~T}}$, que é o tabelado rejeita-se a hipótese alternativa de pelo menos um parâmetro diferente de zero.

Depois de especificado o modelo deve-se verificar se a estrutura final admite a existência de raiz unitária.

$\mathrm{H}_{0}$ : Existe raiz unitária

$\mathrm{H}_{\mathrm{a}}$ : Não existe raiz unitária

$\tau_{\mu}<\tau_{\mu \mathrm{T}}$

Se o valor crítico for menor que o tabelado não se rejeita a hipótese nula de existência de raiz unitária

Deve-se ressaltar que estes procedimentos devem ser feitos para cada variável. Assim, depois da realização destas rotinas para cada variável em estudo - ESALQ, BM\&F e NYBOT, chegou-se aos seguintes resultados:

Tabela 5. Valores Críticos Tabelados para os Parâmetros e Resumo dos Testes Implementados

\begin{tabular}{c|ccccc}
\hline Parâmetro & Teste & 5\% de significância & Esalq & BM\&F & NYBOT \\
Constante & $\tau_{\alpha \mathrm{T}}$ & 3,38 & 2,7644 & 2,5853 & 2,2054 \\
Tendência & $\tau_{\beta \mathrm{T}}$ & 3,11 & 2,5643 & 2,5213 & 1,7727 \\
Significância & $\Phi_{2 \mathrm{~T}}$ & 4,68 & & & \\
conjunta & & & & & \\
Raiz unitária & $\tau_{\mu \mathrm{T}}$ & 1,94 & $-1,4652$ & $-1,4703$ & $-1,6037$ \\
\hline
\end{tabular}

Para a série ESALQ, admitiu-se a existência de uma raiz unitária e o modelo final não incluiu a constante e a tendência, e admitiram-se cinco defasagens. Para se corroborar o número de defasagens a serem incluídas no modelo são utilizados os 
critérios de informação de Akaike (AIC) e Schwartz (SC) ${ }^{21}$, cujos resultados são verificados visualmente por correlogramas.

As tabelas 6, 7 e 8, a seguir, referem-se aos testes de raiz unitária para as séries Esalq, NYBOT e BM\&F, respectivamente. Para cada tabela há um correspondente correlograma no apêndice do trabalho ( $\mathrm{A} 2, \mathrm{~A} 3$ e $\mathrm{A} 4)$. Os correlogramas expressam as séries na primeira diferença e o critério de decisão do lag significativo é o que apresentar o menor critério de informação.

Tabela 6. Teste de Raiz Unitária para a série ESALQ

\begin{tabular}{lllll}
\hline ADF Test Statistic & -1.465247 & $1 \%$ Critical Value* & -2.5681 \\
& & $5 \%$ Critical Value & -1.9398 \\
& $10 \%$ Critical Value & -1.6158 \\
\hline \hline
\end{tabular}

*MacKinnon critical values for rejection of hypothesis of a unit root.

Augmented Dickey-Fuller Test Equation

Dependent Variable: D(LESALQ)

Method: Least Squares

Date: $11 / 19 / 00$ Time: $11: 27$

Sample: 11883

Included observations: 873

\begin{tabular}{lrrrr}
\hline \hline \multicolumn{1}{c}{ Variable } & Coefficient & Std. Error & t-Statistic & Prob. \\
\hline \hline LESALQ(-1) & -0.000115 & $7.84 E-05$ & -1.465247 & 0.1432 \\
D(LESALQ(-1)) & 0.056093 & 0.033665 & 1.666192 & 0.0960 \\
D(LESALQ(-2)) & 0.129007 & 0.033665 & 3.832102 & 0.0001 \\
D(LESALQ(-3)) & 0.168731 & 0.033465 & 5.042003 & 0.0000 \\
D(LESALQ(-4)) & 0.056547 & 0.033667 & 1.679611 & 0.0934 \\
D(LESALQ(-5)) & -0.131141 & 0.033667 & -3.895246 & 0.0001 \\
\hline \hline R-squared & 0.066818 & Mean dependent var & -0.000642 \\
Adjusted R-squared & 0.061436 & S.D. dependent var & 0.009878 \\
S.E. of regression & 0.009570 & Akaike info criterion & -6.453496 \\
Sum squared resid & 0.079406 & Schwarz criterion & -6.420699 \\
Log likelihood & 2822.951 & F-statistic & 12.41585 \\
Durbin-Watson stat & 1.961377 & Prob(F-statistic) & 0.000000 \\
\hline
\end{tabular}

${ }^{21} A I C=-2 l / n+2 k / n$

$S C=-2 l / n+k \log n / n$

onde $\mathrm{k}$ é o número de parâmetros estimados, $\mathrm{n}$ é o número de observaçðes e é o valor da função log likelihood usando $\mathrm{k}$ parâmetros estimados. Como regra geral na determinação do número de defasagens deve-se optar pelo modelo com o menor critério de informação. 
Para a série NYBOT, admitiu-se a existência de uma raiz unitária e o modelo final também não incluiu a constante e a tendência, e foram consideradas treze defasagens (Tabela 7)

Tabela 7. Teste de Raiz Unitária para a série NYBOT

\begin{tabular}{llll}
\hline ADF Test Statistic & -1.603724 & $1 \%$ Critical Value* & -2.5688 \\
& & $5 \%$ Critical Value & -1.9399 \\
& $10 \%$ Critical Value & -1.6159 \\
\hline \hline
\end{tabular}

*MacKinnon critical values for rejection of hypothesis of a unit root.

\begin{tabular}{|c|c|c|c|c|}
\hline \multicolumn{5}{|c|}{$\begin{array}{l}\text { Augmented Dickey-Fuller Test Equation } \\
\text { Dependent Variable: D(LNYBOT) } \\
\text { Method: Least Squares } \\
\text { Date: } 11 / 19 / 00 \text { Time: } 14: 49 \\
\text { Sample(adjusted): } 15883 \\
\text { Included observations: } 658 \\
\text { Excluded observations: } 211 \text { after adjusting endpoints }\end{array}$} \\
\hline Variable & Coefficient & Std. Error & $\mathrm{t}$-Statistic & Prob. \\
\hline LNYBOT(-1) & -0.000209 & 0.000131 & -1.603724 & 0.1093 \\
\hline D(LNYBOT(-1)) & -0.000400 & 0.039445 & -0.010137 & 0.9919 \\
\hline D(LNYBOT(-2)) & -0.012503 & 0.039287 & -0.318257 & 0.7504 \\
\hline D(LNYBOT(-3)) & -0.029045 & 0.039170 & -0.741500 & 0.4587 \\
\hline D(LNYBOT $(-4))$ & 0.032692 & 0.039349 & 0.830835 & 0.4064 \\
\hline $\mathrm{D}(\mathrm{LNYBOT}(-5))$ & -0.003703 & 0.039172 & -0.094539 & 0.9247 \\
\hline D(LNYBOT $(-6))$ & -0.031667 & 0.039353 & -0.804698 & 0.4213 \\
\hline $\mathrm{D}(\mathrm{LNYBOT}(-7))$ & -0.014177 & 0.039049 & -0.363051 & 0.7167 \\
\hline D(LNYBOT(-8)) & 0.032602 & 0.038743 & 0.841511 & 0.4004 \\
\hline D(LNYBOT $(-9))$ & -0.028205 & 0.038769 & -0.727511 & 0.4672 \\
\hline D(LNYBOT $(-10))$ & 0.006542 & 0.038581 & 0.169558 & 0.8654 \\
\hline $\mathrm{D}(\operatorname{LNYBOT}(-11))$ & 0.019442 & 0.038420 & 0.506021 & 0.6130 \\
\hline D(LNYBOT $(-12))$ & -0.027857 & 0.038164 & -0.729917 & 0.4657 \\
\hline D(LNYBOT $(-13))$ & -0.082218 & 0.038031 & -2.161881 & 0.0310 \\
\hline R-squared & 0.013406 & \multicolumn{2}{|c|}{ Mean dependent var } & -0.000778 \\
\hline Adjusted R-squared & -0.006509 & \multicolumn{2}{|c|}{ S.D. dependent var } & 0.013788 \\
\hline S.E. of regression & 0.013832 & \multicolumn{2}{|c|}{ Akaike info criterion } & -5.702551 \\
\hline Sum squared resid & 0.123221 & \multicolumn{2}{|c|}{ Schwarz criterion } & -5.607036 \\
\hline Log likelihood & 1890.139 & \multicolumn{2}{|c|}{ F-statistic } & 0.673158 \\
\hline Durbin-Watson stat & 1.985638 & \multicolumn{2}{|c|}{ Prob(F-statistic) } & 0.790368 \\
\hline
\end{tabular}

Para a série $\mathrm{BM} \& \mathrm{~F}$, também se concluiu pela existência de uma raiz unitária e o modelo final não incluiu a constante e a tendência, e foram consideradas quinze defasagens (Tabela 8 ). 
Tabela 8. Teste Raiz Unitária para a série BM\&F

\begin{tabular}{llll}
\hline ADF Test Statistic & -1.470396 & $1 \%$ Critical Value* & -2.5681 \\
& & $5 \%$ Critical Value & -1.9398 \\
& $10 \%$ Critical Value & -1.6158 \\
\hline \hline
\end{tabular}

*MacKinnon critical values for rejection of hypothesis of a unit root.

Augmented Dickey-Fuller Test Equation

Dependent Variable: $\mathrm{D}$ (LBMF)

Method: Least Squares

Date: $11 / 19 / 00$ Time: $14: 55$

Sample(adjusted): 17883

Included observations: 867 after adjusting endpoints

\begin{tabular}{crrrr}
\hline \hline Variable & Coefficient & Std. Error & t-Statistic & Prob. \\
\hline LBMF(-1) & -0.000123 & $8.36 E-05$ & -1.470396 & 0.1418 \\
D(LBMF(-1)) & 0.021642 & 0.034196 & 0.632866 & 0.5270 \\
D(LBMF(-2)) & 0.047012 & 0.034208 & 1.374284 & 0.1697 \\
D(LBMF(-3)) & 0.049214 & 0.034232 & 1.437636 & 0.1509 \\
D(LBMF(-4)) & -0.010615 & 0.034266 & -0.309770 & 0.7568 \\
D(LBMF(-5)) & 0.036608 & 0.034282 & 1.067836 & 0.2859 \\
D(LBMF(-6)) & -0.033196 & 0.034293 & -0.968011 & 0.3333 \\
D(LBMF(-7)) & -0.040805 & 0.034289 & -1.190025 & 0.2344 \\
D(LBMF(-8)) & 0.043902 & 0.034276 & 1.280830 & 0.2006 \\
D(LBMF(-9)) & -0.030596 & 0.034270 & -0.892799 & 0.3722 \\
D(LBMF(-10)) & -0.025472 & 0.034267 & -0.743348 & 0.4575 \\
D(LBMF(-11)) & -0.053733 & 0.034255 & -1.568601 & 0.1171 \\
D(LBMF(-12)) & -0.022146 & 0.034298 & -0.645700 & 0.5186 \\
D(LBMF(-13)) & -0.027913 & 0.034238 & -0.815259 & 0.4152 \\
D(LBMF(-14)) & 0.007750 & 0.034195 & 0.226654 & 0.8207 \\
D(LBMF(-15)) & 0.067217 & 0.034185 & 1.966288 & 0.0496 \\
\hline \hline R-squared & 0.021986 & Mean dependent var & -0.000514 \\
Adjusted R-squared & 0.004747 & S.D. dependent var & 0.010077 \\
S.E. of regression & 0.010053 & Akaike info criterion & -6.343534 \\
Sum squared resid & 0.086011 & Schwarz criterion & -6.255598 \\
Log likelihood & 2765.922 & F-statistic & 1.275369 \\
Durbin-Watson stat & 2.001032 & Prob(F-statistic) & 0.210908 \\
\hline
\end{tabular}

A hipótese $\mathrm{H}_{0}$ era da existência de raiz unitária, e como notado nas tabelas anteriores todas as variáveis apresentaram seus valores críticos -1.465247 (ESALQ), -1.603724 (NYBOT) e -1.470369 (BM\&F) na área de não rejeição da hipótese nula a 1\%. Os testes permitiram concluir que todas as variáveis são integradas de ordem 1 , e assim podem ser cointegradas.

Dando prosseguimento à implementação do teste de cointegração tem-se que: 
2. Caso $S_{t}$ e $F_{t-1}$ sejam integradas de mesma ordem, o próximo passo é estimar a relação de equilíbrio de longo-prazo. No trabalho foi concluído que as séries são integradas de mesma ordem podendo desta forma realizar o procedimento de cointegração.

$S_{t}=\beta_{0}+\beta_{1} F_{t-1}+u_{t}$

Se as variáveis são cointegradas, uma regressão de mínimos quadrados ordinários (OLS) fornece um estimador "superconsistente" dos parâmetros $\beta_{0}$ e $\beta_{1}$. Para determinar se de fato as variáveis são cointegradas, realiza-se a classificação dos resíduos $\left(\mathrm{u}_{\mathrm{t}}\right)$, que é a série de resíduos estimados da relação de longo-prazo. Se estes desvios de equilíbrio de longo-prazo são estacionários, as seqüências $S_{t}$ e $F_{t-1}$ são cointegradas de ordem $(1 ; 1)$. Seria conveniente a realização de um teste de Dickey-Fuller Aumentado nestes resíduos para determinar a sua ordem de integração. Considere a auto-regressão dos resíduos:

$$
\Delta \hat{u}_{t}=\delta \hat{u}_{t-1}+\sum_{i=1}^{k} \varphi_{i} \Delta \hat{u}_{t-1}+e_{t}
$$

Uma vez que a seqüência $u_{t}$ é o resíduo de uma equação de regressão, não há necessidade de incluir um termo de intercepto, o parâmetro de interesse em (20) é $\delta$. Se não for rejeitada a hipótese nula $\left(\mathrm{H}_{0}: \delta=0\right)$, pode-se concluir que a série contém uma raiz unitária. Assim, as seqüências $S_{t}$ e $F_{t-1}$ não são cointegradas.

Ou de forma alternativa, a rejeição da hipótese nula implica que a seqüência de resíduos é estacionária. Dado que tanto $\mathrm{S}_{\mathrm{t}}$ e $\mathrm{F}_{\mathrm{t}-1}$ são $\mathrm{I}(1)$ e os resíduos são estacionários, conclui-se que as séries são cointegradas de ordem $(1,1)$

A não rejeição da hipótese nula implicará na não existência de cointegração. No presente trabalho o teste de cointegração para ESALQ e BM\&F apresenta valor crítico na área de rejeição, ou seja, há cointegração das variáveis, ao nível de $1 \%$, como notado na tabela 9. Diferentemente do teste realizado para ESALQ e NYBOT, no qual não se 
rejeita a hipótese nula a $1 \%$, portanto as séries não apresentam relação de longo prazo (Tabela 10).

O teste de cointegração de dois estágios de Engle-Granger (1987), baseado nas estatísticas aumentadas de Dickey-Fuller, indicou a existência de cointegração entre as séries ESALQ e BM\&F, assim elas apresentam uma relação de longo prazo, ou seja, há convergência dos preços. No que tange às séries ESALQ e NYBOT, não houve convergência, o que permite inferir que a operação de hedge naquela bolsa é arriscada, no sentido de que as séries não apresentam uma relação de longo prazo.

Tabela 9. Teste de Cointegração para BM\&F e ESALQ

\begin{tabular}{lllll}
\hline CRADF Test Statistic & -3.637929 & $1 \%$ & Critical Value $^{*}$ & -3.4416 \\
& & $5 \%$ Critical Value & -2.8657 \\
& $10 \%$ Critical Value & -2.5690 \\
\hline \hline
\end{tabular}

*MacKinnon critical values for rejection of hypothesis of a unit root.

Augmented Dickey-Fuller Test Equation

Dependent Variable: D(COINTBOLSA)

Method: Least Squares

Date: $11 / 18 / 00$ Time: $20: 56$

Sample(adjusted): 24883

Included observations: 860 after adjusting endpoints

\begin{tabular}{lrrrr}
\hline \multicolumn{1}{c}{ Variable } & Coefficient & \multicolumn{1}{c}{ Std. Error } & \multicolumn{1}{c}{ t-Statistic } & Prob. \\
\hline \hline COINTBOLSA(-1) & -0.036311 & 0.009981 & -3.637929 & 0.0003 \\
D(COINTBOLSA(-1)) & 0.007155 & 0.034244 & 0.208928 & 0.8346 \\
D(COINTBOLSA(-2)) & 0.024681 & 0.033864 & 0.728843 & 0.4663 \\
D(COINTBOLSA(-3)) & 0.058836 & 0.033837 & 1.738817 & 0.0824 \\
D(COINTBOLSA(-4)) & -0.047047 & 0.033883 & -1.388521 & 0.1653 \\
D(COINTBOLSA(-5)) & -0.030239 & 0.033933 & -0.891130 & 0.3731 \\
D(COINTBOLSA(-6)) & 0.111197 & 0.033872 & 3.282900 & 0.0011 \\
D(COINTBOLSA(-7)) & -0.031715 & 0.033963 & -0.933793 & 0.3507 \\
D(COINTBOLSA(-8)) & 0.064928 & 0.033903 & 1.915132 & 0.0558 \\
D(COINTBOLSA(-9)) & 0.032987 & 0.033869 & 0.973934 & 0.3304 \\
D(COINTBOLSA(-10)) & -0.010255 & 0.033873 & -0.302761 & 0.7621 \\
D(COINTBOLSA(-11)) & -0.115736 & 0.033884 & -3.415663 & 0.0007 \\
D(COINTBOLSA(-12)) & -0.109253 & 0.034106 & -3.203338 & 0.0014 \\
\hline R-squared & 0.070480 & Mean dependent var & -0.000143 \\
Adjusted R-squared & 0.057311 & S.D. dependent var & 0.013633 \\
S.E. of regression & 0.013237 & Akaike info criterion & -5.796613 \\
Sum squared resid & 0.148408 & Schwarz criterion & -5.724706 \\
Log likelihood & 2505.544 & F-statistic & 5.351923 \\
Durbin-Watson stat & 2.013437 & Prob(F-statistic) & 0.000000 \\
\hline
\end{tabular}


Tabela 10. Teste de Cointegração para NYBOT e ESALQ

\begin{tabular}{lllll}
\hline CRADF Test Statistic & -2.389714 & $1 \%$ & Critical Value* & $-\mathbf{3 . 4 4 1 6}$ \\
& & $5 \%$ Critical Value & -2.8657 \\
& $10 \%$ Critical Value & -2.5690 \\
\hline \hline
\end{tabular}

*MacKinnon critical values for rejection of hypothesis of a unit root.

Augmented Dickey-Fuller Test Equation

Dependent Variable: D(COINTBOLSANYCE)

Method: Least Squares

Date: $11 / 18 / 00$ Time: $20: 57$

Sample(adjusted): 24883

Included observations: 661

Excluded observations: 199 after adjusting endpoints

\begin{tabular}{|c|c|c|c|c|}
\hline Variable & Coefficient & Std. Error & t-Statistic & Prob. \\
\hline COINTBOLSANYCE(-1) & -0.016280 & 0.006813 & -2.389714 & 0.0171 \\
\hline D(COINTBOLSANYCE $(-1))$ & 0.067607 & 0.039130 & 1.727760 & 0.0845 \\
\hline D(COINTBOLSANYCE $(-2))$ & 0.028841 & 0.039957 & 0.721799 & 0.4707 \\
\hline$D($ COINTBOLSANYCE $(-3))$ & 0.005686 & 0.040076 & 0.141871 & 0.8872 \\
\hline D(COINTBOLSANYCE $(-4))$ & 0.005875 & 0.039713 & 0.147925 & 0.8824 \\
\hline D(COINTBOLSANYCE $(-5))$ & -0.001649 & 0.039897 & -0.041337 & 0.9670 \\
\hline D(COINTBOLSANYCE $(-6))$ & -0.014606 & 0.039491 & -0.369859 & 0.7116 \\
\hline D(COINTBOLSANYCE $(-7))$ & 0.038339 & 0.039459 & 0.971599 & 0.3316 \\
\hline D(COINTBOLSANYCE $(-8))$ & 0.019492 & 0.039726 & 0.490657 & 0.6238 \\
\hline D(COINTBOLSANYCE $(-9))$ & 0.001007 & 0.039490 & 0.025492 & 0.9797 \\
\hline $\begin{array}{c}\mathrm{D}(\text { COINTBOLSANYCE }(- \\
10))\end{array}$ & -0.012997 & 0.039235 & -0.331264 & 0.7406 \\
\hline $\begin{array}{c}\mathrm{D}(\text { COINTBOLSANYCE }(- \\
11))\end{array}$ & 0.027021 & 0.038275 & 0.705952 & 0.4805 \\
\hline $\begin{array}{c}\mathrm{D}(\text { COINTBOLSANYCE(- } \\
12)) \\
\end{array}$ & -0.056149 & 0.037790 & -1.485822 & 0.1378 \\
\hline R-squared & 0.0 & \multicolumn{2}{|c|}{ Mean dependent var } & 0.000264 \\
\hline Adjusted R-squared & 0.001107 & \multicolumn{2}{|c|}{ S.D. dependent var } & 0.017799 \\
\hline S.E. of regression & 0.017789 & \multicolumn{2}{|c|}{ Akaike info criterion } & -5.201035 \\
\hline Sum squared resid & 0.205052 & \multicolumn{2}{|c|}{ Schwarz criterion } & -5.112656 \\
\hline Log likelihood & 1731.942 & \multicolumn{2}{|l|}{ F-statistic } & 1.060980 \\
\hline Durbin-Watson stat & 2.021717 & \multicolumn{2}{|c|}{ Prob(F-statistic) } & 0.390823 \\
\hline
\end{tabular}

\subsection{Procedimento de Johansen}

Vale lembrar que a cointegração entre preços futuro e a vista é condição necessária, mas não suficiente para a aceitação de eficiência de determinado mercado. A hipótese de eficiência necessita que o parâmetro $\delta$ seja igual a 1 - equação (7). 
Para se testar a hipótese de eficiência do mercado Mckenzie \& Holt (1998, p. 4) propõem usar o procedimento multivariado de cointegração de Johansen $(1988,1992)$. Se as restrições $\alpha=0$ e $\delta=1$, não puderem ser rejeitadas então poderá se estar inferindo sobre a existência de eficiência de mercado e previsões não-viesadas. Neste caso (7) reduz-se para:

$u_{t}=S_{t}-\delta F_{t-1}$

A representação de Granger implica que qualquer sistema de cointegração deverá ser reescrito por um modelo de correção de erro ${ }^{22}$

$$
\Delta \mathbf{X}_{t}=\mu+\Pi \mathbf{X}_{t-1}+\sum_{j=1}^{k-1} \Gamma j \Delta \mathbf{X}_{t-j}+\varepsilon_{t}
$$

onde $X_{t}$ é um vetor $(\mathrm{p} \times 1)$ de $\mathrm{I}(1)$ variáveis e $\Pi$ é uma matriz ( $\mathrm{p} \times \mathrm{p}$ ) que tem um rank reduzido quando as variáveis em $X_{t}$ são cointegradas. A matriz $\Pi$ pode ser decomposta em duas matrizes $\alpha$ e $\beta$ de ( $\mathrm{p} \times \mathrm{r}$ ) tal que $\alpha \beta^{\prime}=\Pi$.

As colunas de $\beta$ representam a combinação linear $r$ dos $x_{t}$ que são estacionários ou cointegrados. As correspondentes colunas de $\alpha$ representam os correspondentes coeficientes de correção de erro que podem ser interpretados como velocidade de ajustamento dos parâmetros. Johansen (1988) desenvolveu testes estatísticos para examinar a hipótese nula dos vetores cointegrantes $\mathrm{r}$.

$\mathrm{O}$ termo $\mu$ contém todos os componentes determinísticos do sistema $\mathrm{X}_{\mathrm{t}}$ como uma constante ou um termo de tendência determinística. Se $\mu$ contém somente uma tendência, então $X_{t}$ tem uma tendência quadrática no seu processo gerador. Se $\mu$ contém uma constante, então $X_{t}$ tem uma tendência determinística linear. Se $\mu=0$, é ainda possível incluir uma constante no vetor de cointegração adicionando uma constante ao vetor $\mathrm{X}_{\mathrm{t}}$

\footnotetext{
${ }^{22}$ Baseado em Crowder \& Hamed (1993, p. 935 e 936)
} 
São duas as razões para se testar as propriedades do termo $\mu$. A primeira é que a distribuição assintótica dos testes estatísticos da cointegração dependem da presença de tendências e/ou constantes em $\mu$. E a segunda razão é a de que a hipótese de eficiência especulativa requer o termo de constante igual a zero, que representa uma hipótese testável do parâmetro $\mu$.

Portanto, a utilização do procedimento de Johansen (1988) a fim de se obter as condições necessárias para a hipótese de eficiência em mercados futuros está no fato de que tal procedimento permite a incorporação de restrições para ser testadas.

Tabela 11. Resultados do Procedimento de Johansen

Date: $04 / 22 / 01$ Time: $20: 16$
Sample: 1883
Included observations: 872
$\quad$ Test assumption: Linear deterministic trend in the data
Series: LESALQ LBMF
Lags interval: 1 to 10

\begin{tabular}{|c|c|c|c|c|}
\hline Eigenvalue & $\begin{array}{l}\text { Likelihood } \\
\text { Ratio }\end{array}$ & $\begin{array}{c}5 \text { Percent } \\
\text { Critical Value }\end{array}$ & $\begin{array}{c}1 \text { Percent } \\
\text { Critical Value }\end{array}$ & $\begin{array}{l}\text { Hypothesized } \\
\text { No. of CE(s) }\end{array}$ \\
\hline $\begin{array}{l}0.023419 \\
0.000587\end{array}$ & $\begin{array}{l}21.17592 \\
0.512000\end{array}$ & $\begin{array}{r}15.41 \\
3.76\end{array}$ & $\begin{array}{r}20.04 \\
6.65\end{array}$ & $\begin{array}{l}\text { None } \\
\text { At most } 1\end{array}$ \\
\hline \multicolumn{5}{|c|}{$\begin{array}{l}{ }^{*}\left({ }^{*}\right) \text { denotes rejection of the hypothesis at } 5 \%(1 \%) \text { significance level } \\
\text { L.R. test indicates } 1 \text { cointegrating equation(s) at } 5 \% \text { significance level }\end{array}$} \\
\hline $\begin{array}{c}\text { LESALQ } \\
-0.722414 \\
0.021155\end{array}$ & $\begin{array}{c}\text { LBMF } \\
0.694196 \\
0.156980\end{array}$ & & & \\
\hline $\begin{array}{l}\text { Normalize } \\
\text { LESALQ } \\
1.000000\end{array}$ & $\begin{array}{c}\text { d Cointegrati } \\
\text { LBMF } \\
-0.960940 \\
(0.05367)\end{array}$ & $\begin{array}{c}\text { Coefficients: } 1 \\
\text { C } \\
-0.167052\end{array}$ & Cointegrating $E$ & quation(s) \\
\hline Log likelihood & 5671.072 & & & \\
\hline
\end{tabular}


Os termos $\alpha$ [c]e $\delta$ [LBMF] mostrados na tabela 11 são os coeficientes do intercepto e do preço futuro normalizados das regressões cointegrantes. Mais uma vez os coeficientes parecem estar próximos às restrições de não viés $(0,1)$. Testes formais para testar a hipótese de não viés foram realizados usando os testes de razão de verossimilhança de Johansen (1995) no qual se testa as restrições para os parâmetros $\alpha \mathrm{e}$ $\delta$. Os resultados como mostrado na tabela 11 indicam que a hipótese nula testada individualmente de $\alpha=0$, e $\delta=1$ não podem ser rejeitadas a $1 \%$ de significância. Este resultado sugere que o preço futuro do algodão em pluma dá uma previsão não viesada do futuro preço a vista na data de vencimento do contrato.

A tabela 11 apresenta, então, os resultados da análise de cointegração de Johansen. A hipótese nula de nenhum vetor de cointegração é rejeitada a níveis altos de significância, mas a hipótese de mais de um vetor de cointegração não pode ser rejeitada. Ademais, os parâmetros estimados para o preço futuro são insignificantemente diferente da unidade, o estimado para a constante é insignificantemente diferente de zero, e os resíduos não são significativamente diferentes de um ruído branco. As restrições impostas pela hipótese de eficiência de mercado não puderam ser rejeitadas.

A corroboração da hipótese de eficiência de mercado conduz a algumas implicações. Primeiro, que o preço futuro BM\&F foi um previsor não viesado do correspondente preço a vista. Segundo, não houve evidência de um prêmio de risco e nenhuma evidência de que os erros de previsão passados fossem usados para predizer o futuro preço a vista.

Inferências sobre a relação de causalidade entre os preços a vista e futuro do algodão em pluma podem ser feitos pela análise dos coeficientes de erro. O termo de correção de erro do preço a vista é estatisticamente insignificante implicando que os erros passados não granger causam mudanças no preço a vista. Mas o coeficiente de correção de erro do preço futuro é significante, o que implica que em equilibrio os erros passados granger causam os preços futuros. Isto significa que os erros de previsão passados afetam as previsões atuais do preço a vista, e não o preço a vista - que é determinado pelos fundamentos de oferta e demanda. 
No anexo do trabalho está o vetor de correção de erro proposto para as séries Esalq e BM\&F. Foram considerados 13 defasagens para as variáveis, baseados nos resultados dos testes de raiz unitária. Todas as defasagens são significantes a $5 \%$. 


\section{CONCLUSÕES}

O trabalho teve por objetivo final verificar qual a opção de hedge foi mais eficiente para o hedger (produtor e indústria de fiação) no período de $2 / 1 / 1997$ a 1/7/2000. Analisou-se duas possibilidades: na BM\&F e na NYBOT.

A metodologia para verificação da hipótese de eficiência de mercado seguiu o procedimento de cointegração. A análise procurou perceber se as séries de preço a vista e futuro cointegravam, isto é, mantinham uma relação de longo prazo. Se tal fato fosse comprovado, seriam testadas as restrições concernentes à eficiência de mercado.

No caso da análise da opção de hedge feita na BM\&F verificou-se a cointegração das séries, através do procedimento de dois estágios de Engle \& Granger (1987). No entanto a existência de uma relação de longo prazo entre as variáveis não implica num contrato futuro eficiente para aquele preço a vista. Para tanto faz-se necessário testar o parâmetro $\delta$ igual a 1 . Para tal verificação será utilizado o procedimento de Johansen (1988) que permite a inclusão de restrições na matriz a fim de testar as restrições especificadas em (7.1).

Para o periodo analisado o contrato de algodão em pluma da BM\&F foi um instrumento de seguro de preços eficiente para o hedger nacional, no sentido de que o preço futuro do algodão em pluma forneceu uma previsão não viesada do futuro preço a vista na data de vencimento do contrato. Outra conclusão é a de que não houve evidência de um prêmio de risco e nenhuma evidência de que os erros de previsão passados fossem usados para predizer o futuro preço a vista.

No que tange ao hedge realizado na NYBOT tem-se que a hipótese da não relação entre o mercado a vista brasileiro de algodão e o da bolsa NYBOT foi 
comprovada através do procedimento de cálculo da eficiência de hedge. Sendo assim a interpretação do modelo de Black (1996), descrito na seção 3.4, que aliava o fracasso de um contrato futuro à troca de um percentual de risco por uma redução no custo de liquidez fica anulada.

Como as séries Esalq e NYBOT não cointegram, a opção por hedge NYBOT mostrou-se totalmente arriscada. Assim, pode-se inferir que a liquidez de Nova York não foi um fator de entrave ao desenvolvimento do contrato de algodão da BM\&F, pois os hedgers só iriam optar pela liquidez da bolsa norte-americana se houvesse um mínimo de risco. Entretanto, no caso analisado o risco foi representativo.

Este resultado já era esperado pois a NYBOT reflete o comportamento do mercado norte-americano e mundial de algodão. O Brasil por possuir uma formação de preços distinta e pelo fato de não ter importância significativa no mercado internacional não terá seu comportamento interno absorvido pelas cotações da NYBOT. Assim, para o produtor nacional e para as indústrias de fiação o melhor instrumento de hedge é o da BM\&F,

É necessário ressaltar que apesar da BM\&F ter proporcionado durante o periodo analisado para o hedger um instrumento de seguro de preços eficiente, desde julho de 2000 não há negociações, sendo que desde 1998 o volume já era decrescente. Assim, os hedgers nacionais estão órfãos de um instrumento de seguro de preços.

A fim de entender porque o instrumento não tem sido utilizado, apesar de ter cumprido a função de sinalização de preços, é preciso prestar atenção nas hipóteses levantadas ao se analisar os capítulos 2 e 3 , que decorrem especialmente da questão da intervenção governamental, da concentração tanto na parte agrícola como na industrial, e ao fato da indústria já estar hedgeada, pois a possibilidade de diferenciação de produtos finais é grande, cite exemplos como cama, mesa, banho, artigos hospitalares, malhas, roupas íntimas, moda praia, jeans, tecidos, etc. Assim, não importa o preço ao qual irão adquirir a pluma, pois terão condições de repassá-lo ao consumidor. Cabe como estudo mais aprofundado testar a veracidade de tais hipóteses. 
O trabalho não levou em consideração a possibilidade de encerramento dos contratos antes do vencimento do mesmo. Tal procedimento deveu-se ao fato do contrato de algodão em pluma da BM\&F ser caracterizado por encerramentos próximo ao último dia de negociação. Além disso, o contrato em análise era liquidado por um Indicador de preços do mercado a vista - O Indicador do Algodão em Pluma Esalq/BM\&F.

Em 1999 houve uma alteração contratual que anulou a liquidação por Indicador de Preços e estabeleceu a liquidação por entrega. Tal medida foi um avanço para o contrato no sentido de permitir aos hedgers arbitrar o preço local e o preço na BM\&F. Se verificada qualquer distorção entre tais preços poderiam entregar ou adquirir o produto na bolsa, a liquidação por entrega permite uma melhor convergência dos preços.

Neste sentido, seria interessante como continuidade deste trabalho verificar os riscos de encerrar a posição em bolsa antes do vencimento do contrato, pois como os preços futuros referem-se a uma determinada data no futuro, ao se encerrar a posição antes do vencimento poderá significar riscos para o hedger. 


\section{REFERÊNCIAS BIBLIOGRÁFICAS}

ARBEX, M.A.; CARVALHO, V.D.Eficiência do mercado futuro de café brasileiro, no período de 1992 a 1998. Revista de Economia e Sociologia Rural, v 37, n 1, p. 97 113. 1999.

ARBEX, M.A.; ROTATORI, W.L. Eficiência em mercados futuros, prêmio de risco e bandas de câmbio no Brasil. Estudos Econômicos, v 4. 2000.

BLACK, D. Success and failure of futures contracts: theory and empirical evidence. New York, v 1, 1986. 70p. (Monograph Series in Finance and Economics).

Companhia Nacional de Abastecimento (CONAB). Informativo agropecuário. Brasília, v 3, 2001. 64p.

CROWDER, W.J.; HAMED, A. A cointegration test for oil futures market efficiency. Journal of Futures Markets, v.13, n.8. p. 933-941, 1993.

DICKEY, D.A.; FULLER, W.A. Distribution of the estimators for autoregressive time series with a unit root. Journal of the American Statistical Association, v 74, n 366, p. $427-431,1979$.

ENDERS, W. Applied econometric time series. New York: John Wiley. 1995. 433p.

ENGLE, R.F.; GRANGER, C.W.J. Cointegration and error correction: representation, estimation, and testing. Econometrica, v 35, n 1, p. 251-276, 1987.

FERREIRA FILHO, J.B.S.; DE ZEN, S. Estudo sobre a comercialização do algodão em pluma. Piracicaba: ESALQ, CEPEA, USP. 1998. 30p.

GUJARATI, H. Basic econometrics. 2. ed. New York: McGraw-Hill . 1995. 780p.

HAMILTON, J.D. Time series analysis. Princeton University Press. 1994. 650 p.

HIERONYMUS, T.A. Economics of futures trading for commercial and personal profit. 2. ed. New York: Commodity Research Bureau. 1977. 368 p. 
HULL, J.C. Introduction to futures \& options markets. 2. ed, Prentice Hall, 1995. $448 \mathrm{p}$.

JAYO, M., NUNES, R. Competitividade do sistema agroindustrial do algodão. In: Competitividade no agribusiness brasileiro. São Paulo, USP, FEA, FIA, PENSA. 1998. 87p.

JOHANSEN, S. Statistical analysis of cointegration vectors. Journal of Economic Dynamics and Control, v. 12, p. 231-254, 1988.

JOHANSEN, S. Cointegration in partial systems and the efficiency of single-equation analysis. Journal of Econometrics. v. 52, n 3, p. 389-402, 1992.

JOHANSEN, S. Likelihood based inference in cointegrated vector auto-regressive models. Oxford: Oxford University Press, 1995.

KWIATKOWSKI, D., PHILLIPS, P.C.B., SCHMIDT, P.; SHIN, Y. Testing the null hypothesis of stationarity against the alternative of unit root. Journal of Econometrics, v. 54, p. 159-187, 1992

LAZZARINI, S.G. Inovação e organização de bolsas de futuros: teoria e evidências no agribusiness brasileiro. São Paulo, 1997. 216p. Dissertação (Mestrado) - Faculdade de Economia e Administração, Universidade de São Paulo.

LEUTHOLD, R.M.; JUNKUS, J.C.; CORDIER, J.E. The theory and practice of futures markets. Lexington Books, 1989. 410p.

LIEN, D. D. The effect of the cointegration relationship on futures hedging: a note. Journal of Futures Markets, v. 16, n. 7, p. 773-780, 1996.

MARTIGNON, L.M.; DE ZEN, S. Análise do uso de mercados futuros de algodão em substituição ao prêmio de escoamento de produto. (compact disc). In: CONGRESSO DE ECONOMIA E SOCIOLOGIA RURAL, 38. Rio de Janeiro, 2000. Brasília: SOBER, 2000.

MARTITS, L.A. Avaliação do uso de derivativos agrícolas no Brasil: os fatores que determinam o sucesso ou fracasso dos contratos negociados na BM\&F. São Paulo, 1998. 208p. Dissertação (Mestrado) - Escola de Administração de Empresas de São Paulo, Fundação Getúlio Vargas.

MCKENZIE, A.M; HOLT, M.T. Market efficiency in agricultural futures markets. In: 1998 American Agricultural Economics Association Annual Meeting in Salt Lake City. 1998. 14p. 
MICHELLON, E. Cadeia produtiva e desenvolvimento regional: uma análise a partir do setor têxtil do algodão no noroeste do Paraná. Maringá: Clichetec, 1999. 222p.

MORAES, M. P. O futuro da agricultura está no mercado. Folha de São Paulo, São Paulo, 05 set. 1999. p. 1-3.

PENNINGS, J.M.E.; LEUTHOLD, R.M. Commodity futures contract viability: a multidisciplinary approach. Urbana: University of Illinois. (Paper, 99-02). 1999. 40p.

PHILLIPS, P.C.B.; PERRON, P. Testing for unit root in time series regression. Biometrika v. 75, p.335-346, 1988.

RESENHA BM\&F, n. 143, Jan-Fev, 2001. 70p.

SILBER, W.L. Innovation, competition and new contract design in futures markets. Journal of Futures Markets. v. 1, n. 2, p. 123-155, summer. 1981.

SOUZA, W.A. Determinantes da viabilidade de mercados futuros agropecuários no âmbito do Mercosul. Piracicaba, 1998. 136p. Tese (Doutorado) - Escola Superior de Agricultura "Luiz de Queiroz" - Universidade de São Paulo.

TEIXEIRA, M.A. Mercados futuros: fundamentos e características operacionais. São Paulo: Bolsa de Mercadorias \& Futuros. 1992. 50p.

TELSER, L.G. \& HIGINBOTHAM, H.N. Organized futures market: costs and benefits. Journal of Political Economy, v. 85, n. 5, p. 969-1000, 1977.

TEWELES, R.J.; JONES, F.J. The futures game: who wins? who loses? why? New York: McGraw-Hill. 1987.649p.

TSETSEKOS, G.; VARANGIS, P. The structure of derivatives exchange: lessons from developed and emerging markets. Washington: The World Bank, Development Research Group. 1997. 28p.

URBAN, M.L.P. et al. Desenvolvimento da produção de têxteis de algodão no Brasil. Informações Econômicas. v. 25, n. 12, p. 11-28, dez. 1995.

WILLIAMSON, O.E. The economic institutions of capitalism. New York: The Free Press, 1985. 450p. 
APÊNDICE 
A1 - Vetor de Correção de Erro

\begin{tabular}{cc}
\hline \hline Cointegrating Eq: & CointEq1 \\
\hline \hline LESALQ(-1) & 1.000000 \\
LBMF(-1) & -0.961096 \\
& $(0.06794)$ \\
& $(-14.1471)$ \\
C & -0.166074
\end{tabular}

\begin{tabular}{ccc}
\hline \hline Error Correction: & D(LESALQ) & D(LBMF) \\
\hline \hline CointEq1 & -0.016235 & 0.017645 \\
& $(0.00672)$ & $(0.00738)$ \\
& $(-2.41584)$ & $(2.39233)$ \\
& & \\
D(LESALQ(-1)) & 0.001155 & 0.010954 \\
& $(0.03437)$ & $(0.03773)$ \\
& $(0.03361)$ & $(0.29035)$ \\
D(LESALQ(-2)) & 0.085588 & 0.081505 \\
& $(0.03409)$ & $(0.03741)$ \\
& $(2.51090)$ & $(2.17859)$ \\
D(LESALQ(-3)) & 0.126645 & 0.030441 \\
& $(0.03416)$ & $(0.03750)$ \\
& $(3.70701)$ & $(0.81185)$ \\
& & \\
D(LESALQ(-4)) & 0.046200 & -0.010640 \\
& $(0.03431)$ & $(0.03766)$ \\
& $(1.34639)$ & $(-0.28251)$ \\
D(LESALQ(-5)) & -0.123875 & -0.023804 \\
& $(0.03432)$ & $(0.03767)$ \\
& $(-3.60898)$ & $(-0.63187)$ \\
D(LESALQ(-6)) & 0.175939 & -0.071719 \\
& $(0.03458)$ & $(0.03795)$ \\
& $(5.08846)$ & $(-1.88989)$ \\
D(LESALQ(-7)) & 0.059748 & 0.063761 \\
& $(0.03512)$ & $(0.03854)$ \\
& $(1.70129)$ & $(1.65420)$ \\
D(LESALQ(-8)) & -0.017560 & -0.126836 \\
& $(0.03473)$ & $(0.03812)$ \\
& $(-0.50555)$ & $(-3.32715)$ \\
& &
\end{tabular}




\begin{tabular}{|c|c|c|}
\hline$D(L E S A L Q(-9))$ & $\begin{array}{c}-0.021033 \\
(0.03462) \\
(-0.60756)\end{array}$ & $\begin{array}{c}-0.128045 \\
(0.03800) \\
(-3.37000)\end{array}$ \\
\hline$D(L E S A L Q(-10))$ & $\begin{array}{c}-0.053162 \\
(0.03424) \\
(-1.55240)\end{array}$ & $\begin{array}{c}-0.025417 \\
(0.03759) \\
(-0.67626)\end{array}$ \\
\hline$D(L E S A L Q(-11))$ & $\begin{array}{c}-0.028340 \\
(0.03379) \\
(-0.83868)\end{array}$ & $\begin{array}{l}0.035362 \\
(0.03709) \\
(0.95347)\end{array}$ \\
\hline D(LESALQ $(-12))$ & $\begin{array}{c}-0.101617 \\
(0.03343) \\
(-3.03923)\end{array}$ & $\begin{array}{l}0.098326 \\
(0.03670) \\
(2.67944)\end{array}$ \\
\hline D(LESALQ(-13)) & $\begin{array}{c}-0.087895 \\
(0.03377) \\
(-2.60285)\end{array}$ & $\begin{array}{c}0.006353 \\
(0.03706) \\
(0.17141)\end{array}$ \\
\hline D(LBMF(-1)) & $\begin{array}{l}0.052934 \\
(0.03154) \\
(1.67830)\end{array}$ & $\begin{array}{c}0.021624 \\
(0.03462) \\
(0.62465)\end{array}$ \\
\hline $\mathrm{D}($ LBMF $(-2))$ & $\begin{array}{l}0.101510 \\
(0.03138) \\
(3.23495)\end{array}$ & $\begin{array}{l}0.053046 \\
(0.03444) \\
(1.54022)\end{array}$ \\
\hline D(LBMF(-3)) & $\begin{array}{l}0.092504 \\
(0.03150) \\
(2.93695)\end{array}$ & $\begin{array}{l}0.055569 \\
(0.03457) \\
(1.60747)\end{array}$ \\
\hline$D(\operatorname{LBMF}(-4))$ & $\begin{array}{l}0.145583 \\
(0.03168) \\
(4.59577)\end{array}$ & $\begin{array}{c}-0.010592 \\
(0.03477) \\
(-0.30465)\end{array}$ \\
\hline D(LBMF $(-5))$ & $\begin{array}{l}0.013073 \\
(0.03207) \\
(0.40766)\end{array}$ & $\begin{array}{l}0.025023 \\
(0.03520) \\
(0.71096)\end{array}$ \\
\hline$D($ LBMF $(-6))$ & $\begin{array}{c}-0.028347 \\
(0.03201) \\
(-0.88549)\end{array}$ & $\begin{array}{c}-0.037240 \\
(0.03514) \\
(-1.05990)\end{array}$ \\
\hline D(LBMF $(-7))$ & $\begin{array}{l}0.014915 \\
(0.03192) \\
(0.46731)\end{array}$ & $\begin{array}{c}-0.031860 \\
(0.03503) \\
(-0.90952)\end{array}$ \\
\hline $\mathrm{D}(\mathrm{LBMF}(-8))$ & $\begin{array}{c}-0.017743 \\
(0.03189) \\
(-0.55647)\end{array}$ & $\begin{array}{l}0.050835 \\
(0.03500) \\
(1.45259)\end{array}$ \\
\hline
\end{tabular}




\begin{tabular}{|c|c|c|}
\hline $\mathrm{D}(\mathrm{LBMF}(-9))$ & $\begin{array}{c}-0.019664 \\
(0.03192) \\
(-0.61598)\end{array}$ & $\begin{array}{c}-0.023995 \\
(0.03504) \\
(-0.68481)\end{array}$ \\
\hline$D(\operatorname{LBMF}(-10))$ & $\begin{array}{l}-0.034216 \\
(0.03192) \\
(-1.07201)\end{array}$ & $\begin{array}{l}0.001454 \\
(0.03503) \\
(0.04150)\end{array}$ \\
\hline $\mathrm{D}(\operatorname{LBM} F(-11))$ & $\begin{array}{l}0.062838 \\
(0.03190) \\
(1.96997)\end{array}$ & $\begin{array}{l}-0.032413 \\
(0.03501) \\
(-0.92585)\end{array}$ \\
\hline$D(L B M F(-12))$ & $\begin{array}{l}0.014502 \\
(0.03196) \\
(0.45369)\end{array}$ & $\begin{array}{l}0.017386 \\
(0.03508) \\
(0.49560)\end{array}$ \\
\hline $\mathrm{D}(\operatorname{LBM} F(-13))$ & $\begin{array}{l}0.016509 \\
(0.03193) \\
(0.51704)\end{array}$ & $\begin{array}{c}-0.004851 \\
(0.03505) \\
(-0.13841)\end{array}$ \\
\hline C & $\begin{array}{c}-0.000385 \\
(0.00031) \\
(-1.22744)\end{array}$ & $\begin{array}{c}-0.000505 \\
(0.00034) \\
(-1.46921)\end{array}$ \\
\hline $\begin{array}{l}\text { R-squared } \\
\text { Adj. R-squared } \\
\text { Sum sq. resids } \\
\text { S.E. equation } \\
\text { Log likelihood } \\
\text { Akaike AIC } \\
\text { Schwarz SC } \\
\text { Mean dependent } \\
\text { S.D. dependent }\end{array}$ & $\begin{array}{c}0.195477 \\
0.169648 \\
0.068389 \\
0.009018 \\
2872.917 \\
2872.981 \\
2873.135 \\
-0.000640 \\
0.009896\end{array}$ & $\begin{array}{c}0.063309 \\
0.033237 \\
0.082383 \\
0.009897 \\
2792.029 \\
2792.094 \\
2792.247 \\
-0.000510 \\
0.010066\end{array}$ \\
\hline \multicolumn{2}{|c|}{$\begin{array}{l}\text { Log Likelihood } \\
\text { Akaike Information Criteria } \\
\text { Schwarz Criteria }\end{array}$} & $\begin{array}{l}5665.428 \\
5665.561 \\
5665.879\end{array}$ \\
\hline
\end{tabular}


A2 - Correlograma D(LESALQ)

Date: 06/24/01 Time: 12:28

Sample: 1883

Included observations: 882

\begin{tabular}{|c|c|c|c|c|c|c|}
\hline Autocorrelation & Partial Correlation & & $A C$ & PAC & Q-Stat & Prob \\
\hline.$^{*}$ &.$j^{*}$ & 1 & 0.089 & 0.089 & 6.9548 & 0.008 \\
\hline$\left.\right|^{*}$ & $j^{*}$ & 2 & 0.134 & 0.127 & 22.755 & 0.000 \\
\hline$j^{\star}$ & & 3 & 0.175 & 0.157 & 49.920 & 0.000 \\
\hline . & . & 4 & 0.087 & 0.050 & 56.652 & 0.000 \\
\hline$*$ & *l. & 5 & -0.076 & -0.131 & 61.783 & 0.000 \\
\hline.$\left.\right|^{*}$ &.$j^{*}$ & 6 & 0.169 & 0.146 & 87.142 & 0.000 \\
\hline . & . & 7 & 0.039 & 0.024 & 88.469 & 0.000 \\
\hline. & . & & -0.032 & -0.049 & 89.382 & 0.000 \\
\hline . & $* 1$. & 9 & -0.025 & -0.067 & 89.923 & 0.000 \\
\hline *1. & $\star 1$. & 10 & -0.080 & -0.113 & 95.656 & 0.000 \\
\hline$\star$ & $\star 1$. & 11. & -0.126 & -0.066 & 109.90 & 0.000 \\
\hline$*$ & $* 1$. & 12 & -0.153 & -0.131 & 130.93 & 0.000 \\
\hline *. & $\star 1$. & 13 & -0.137 & -0.095 & 147.74 & 0.000 \\
\hline . &.$^{\star}$ & 14 & 0.002 & 0.100 & 147.75 & 0.000 \\
\hline. & $j^{\star}$ & 15 & -0.005 & 0.076 & 147.77 & 0.000 \\
\hline . & . & 16 & -0.047 & 0.001 & 149.76 & 0.000 \\
\hline .1. & .1 & 17. & -0.018 & -0.021 & 150.07 & 0.000 \\
\hline .1 & . & 18 & 0.023 & 0.045 & 150.53 & 0.000 \\
\hline$\star$ & . & 19 & -0.069 & -0.017 & 154.83 & 0.000 \\
\hline . & . & 20 & 0.060 & 0.047 & 158.11 & 0.000 \\
\hline . & . & 21 & 0.062 & 0.009 & 161.54 & 0.000 \\
\hline . & . & 22 & 0.038 & -0.001 & 162.88 & 0.000 \\
\hline$j^{\star}$ &. & 23 & 0.069 & 0.025 & 167.15 & 0.000 \\
\hline . & . & 24 & 0.090 & 0.009 & 174.46 & 0.000 \\
\hline 1. & .1. & 25 & -0.008 & -0.036 & 174.52 & 0.000 \\
\hline . & .1. & 26 & -0.006 & -0.037 & 174.55 & 0.000 \\
\hline .1. & . & 27 & -0.016 & -0.032 & 174.78 & 0.000 \\
\hline .1. & .1. & 28 & -0.035 & -0.029 & 175.88 & 0.000 \\
\hline$j^{*}$ & $f^{*}$ & 29 & 0.091 & 0.110 & 183.46 & 0.000 \\
\hline . & .1. & 30 & 0.003 & -0.001 & 183.47 & 0.000 \\
\hline .1. & 1. & 31. & -0.016 & -0.012 & 183.69 & 0.000 \\
\hline . & i. & 32 & -0.047 & -0.055 & 185.68 & 0.000 \\
\hline . &. & 33 & -0.013 & 0.025 & 185.85 & 0.000 \\
\hline *l. & . & 34 & -0.077 & -0.002 & 191.25 & 0.000 \\
\hline. & . & 35 & -0.034 & -0.041 & 192.30 & 0.000 \\
\hline .1. & $f^{n}$ & 36 & 0.063 & 0.092 & 196.01 & 0.000 \\
\hline
\end{tabular}




\section{A3 - Correlograma D(LNYBOT)}

Date: 06/24/01 Time: 12:26

Sample: 1883

Included observations: 851

\begin{tabular}{|c|c|c|c|c|c|}
\hline Autocorrelation & Partial Correlation & $A C$ & PAC & Q-Stat & Prob \\
\hline 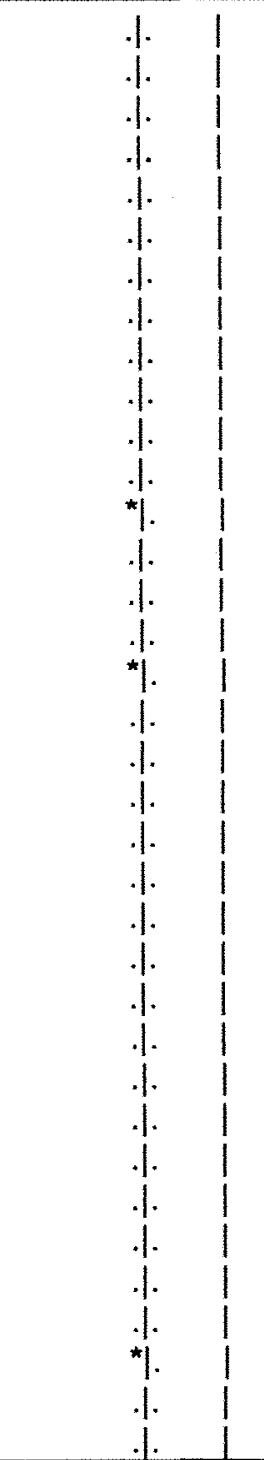 & 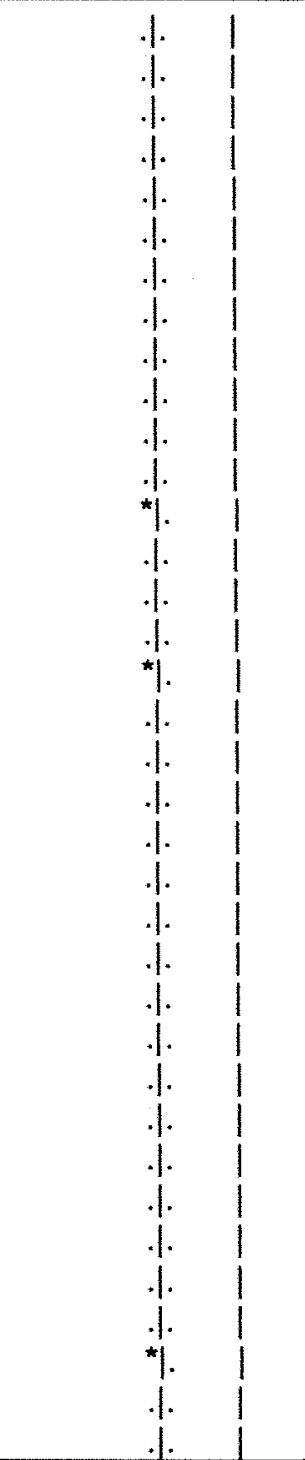 & $\begin{array}{rr}1 & 0.003 \\
2 & -0.011 \\
3 & -0.027 \\
4 & 0.033 \\
5 & 0.014 \\
6 & -0.026 \\
7 & -0.003 \\
8 & 0.037 \\
9 & -0.015 \\
10 & 0.003 \\
11 & 0.005 \\
12 & -0.009 \\
13 & -0.067 \\
14 & 0.007 \\
15 & 0.016 \\
16 & 0.031 \\
17 & -0.075 \\
18 & -0.032 \\
19 & -0.037 \\
20 & 0.018 \\
21 & 0.057 \\
22 & -0.032 \\
23 & -0.017 \\
24 & 0.024 \\
25 & 0.006 \\
26 & -0.035 \\
27 & -0.021 \\
28 & -0.032 \\
29 & 0.051 \\
30 & 0.001 \\
31 & -0.018 \\
32 & 0.008 \\
33 & -0.025 \\
34 & -0.103 \\
35 & 0.012 \\
36 & -0.012\end{array}$ & $\begin{array}{r}0.003 \\
-0.011 \\
-0.027 \\
0.033 \\
0.013 \\
-0.026 \\
-0.001 \\
0.037 \\
-0.018 \\
0.005 \\
0.008 \\
-0.013 \\
-0.067 \\
0.010 \\
0.014 \\
0.026 \\
-0.069 \\
-0.030 \\
-0.042 \\
0.013 \\
0.064 \\
-0.032 \\
-0.017 \\
0.024 \\
0.003 \\
-0.040 \\
-0.011 \\
-0.034 \\
0.046 \\
-0.004 \\
-0.022 \\
0.005 \\
-0.019 \\
-0.102 \\
0.009 \\
-0.023\end{array}$ & $\begin{array}{l}0.0065 \\
0.1026 \\
0.7249 \\
1.6580 \\
1.8265 \\
2.3893 \\
2.3990 \\
3.5952 \\
3.8008 \\
3.8103 \\
3.8354 \\
3.9053 \\
7.7945 \\
7.8354 \\
8.0703 \\
8.8928 \\
13.838 \\
14.716 \\
15.895 \\
16.184 \\
18.982 \\
19.893 \\
20.154 \\
20.654 \\
20.688 \\
21.782 \\
22.165 \\
23.067 \\
25.320 \\
25.320 \\
25.609 \\
25.664 \\
26.201 \\
35.681 \\
35.818 \\
35.954\end{array}$ & $\begin{array}{l}0.936 \\
0.950 \\
0.867 \\
0.798 \\
0.873 \\
0.881 \\
0.935 \\
0.892 \\
0.924 \\
0.955 \\
0.974 \\
0.985 \\
0.857 \\
0.898 \\
0.921 \\
0.918 \\
0.679 \\
0.681 \\
0.664 \\
0.705 \\
0.586 \\
0.590 \\
0.633 \\
0.659 \\
0.710 \\
0.701 \\
0.729 \\
0.730 \\
0.662 \\
0.709 \\
0.740 \\
0.778 \\
0.794 \\
0.389 \\
0.430 \\
0.471\end{array}$ \\
\hline
\end{tabular}


A4 - Correlograma D(LBM\&F)

Date: 06/24/01 Time: 12:28

Sample: 1883

Included observations: 882

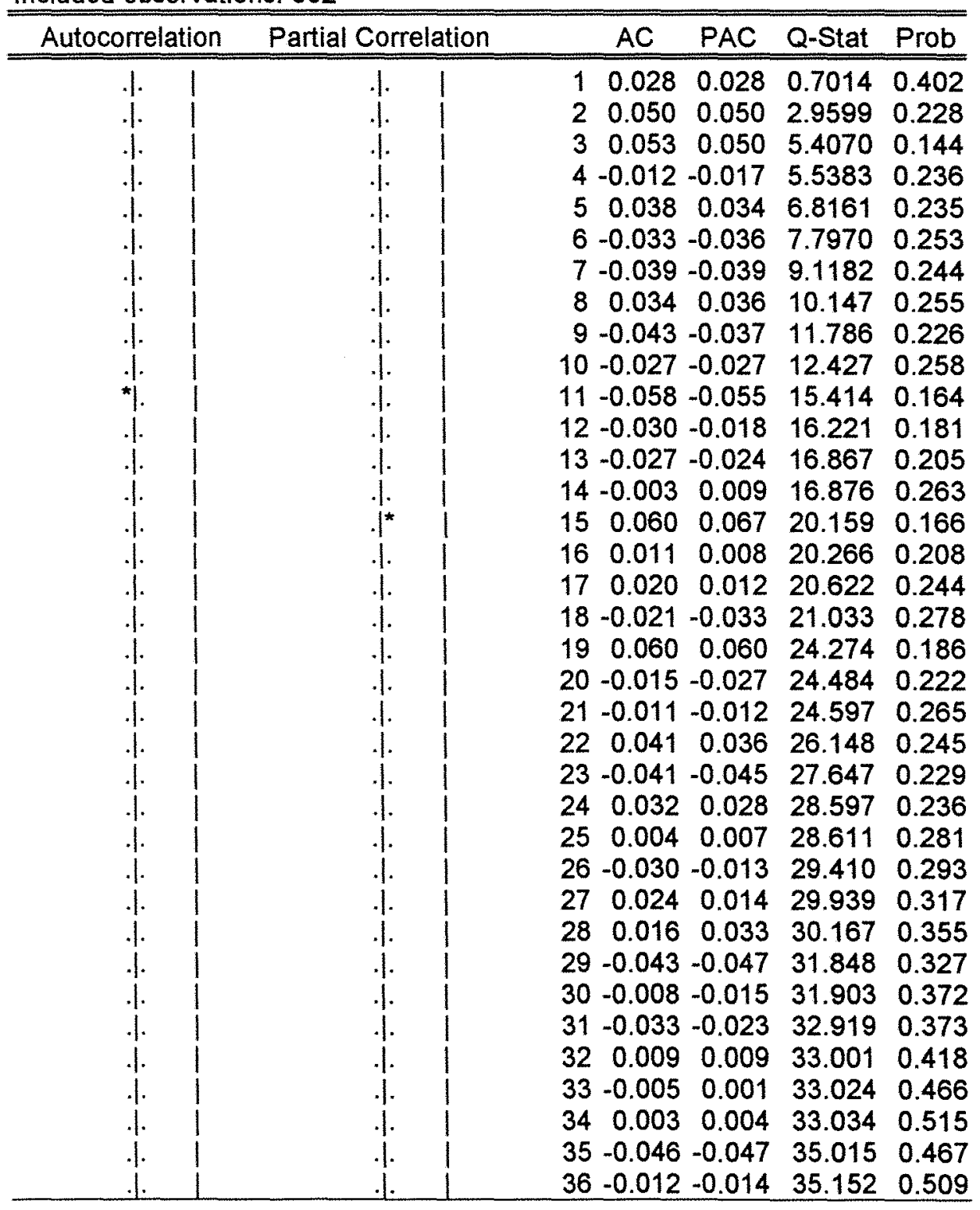

